\title{
Estados Unidos y América Latina bajo la presidencia de Carter*
}

Este artículo se divide en seis secciones más una breve conclusión. Estos párrafos se refieren a las siguientes materias: el pasaclo hecho presente en las relaciones interamericanas; problemas estructurales que enfrenta el gobierno de Carter; características generales de la po. lítica exterior de Carter; los postulados cloctrinarios de Carter sobre América Latina; los hombres cletrás de la política hacia Iberoamérica; y los problemas que muestran las relaciones interamericanas en 1977.

A menudo los periodistas latinoamericanos deben recurrir a juegos de malabarismo (o "palabrarismo") para desentrañar algún contenido a las declaraciones norteamericanas sobre Iberoamérica ${ }^{ \pm}$y desper-

- Este artículo se publica simultáneamente en la Revista de Politica Internacional del Centro de Estudios Internacionales, Madrid.

${ }^{1}$ El primer problema con que uno se topa al escribir sobre las relaciones entre Estados Unidos e Xberoamérica es literario. En efecto, es difícil dar un nombre apropiado a la potencia norteamericana y, aún más, encontrar un gentilicio que, además de ser adecuado, suene bien al oido del lector. En otro artículo "American World Play". En: The Harvard Independent, Noviembre 13" 19, 1975. P. 7) me he refericlo más extensamente a esta materia. Aqui basta con señalar que en este estudio invariablemente cuando se dice "norteamericano" significa perteneciente a Estados Unidos de América solamente. Ocasionalmente se usa la expresión "cstadounidense", más correcta, pero menos agradable y popularizada:

América Latina es el nombre que los habitantes de ese continente dan a éste. Además, es la expresión con que esa región es individualizada en Estados Unidos. Quizás una manera más correcta es referirse a ésta como Iberoamérica, palabra que, por ejemplo, preferia el insigne historiador chileno Jaime Eyzaguirre. En este estudio, ambas expresiones se emplean alternativamente, haciéndose una concesión entre la pureza del idioma y la práctica de éste. Ahora bien, ¿̇se debe comprender el Caribe como parte de América Latina? Este es un problema difícil, como lo sabe cualquiera que haya escrito sobre problemas latinoamericanos (desde luego, los autores que sirven de referencia en esta materia no hacen comúnmente distinción entre estos dos términos, y ora se dice América Latina er un sentido amplio y ora restringido). Aquí, salvo que del contexto se comprenda otra cosa, se preferirá la acepción amplia de América Latina, á pesar que el autor está consciente de las especiales características culturales, históricas, raciales, etc., que existen en el Caribe. 
tar el interés de los lectores en comentarios que asemejan discusiones de teólogos. Los diarios tienen que cledicar grandes titulares a la política de Estados Unidos hacia América Latina porque este país es, descle 1914 (y especialmente 1929), el mayor inversionista en la región ${ }^{2}$, lo cual se traduce en una inmensurable influencia política, económica y militar. Al mismo tiempo, los iberoamericanos, a pesar de sus divergencias políticas, ya no creen en espejismos porque tie-

- En 1796, las exportaciones estadounidenses a América Latina sólo representaban el 3 por ciento de las exportaciones totales de Estados Unidos (Abraham F. Lowenthal: The United Stales and Lalin America; Ending the Hegemonic Presumption. En: Vol. 55 Foreign Affairs, P. 201, 1976).

El gran aumento de capital norteamericano en Iberoamérica a partir de comienzos de este siglo, corresponde a la evolución de la naturaleza del capitalismo en Estados Unidos. En efecto, a partir de comienzos del s'glo pasado se produjo en ese país una transformación del capitalismo mercantil al capitalismo industrial. Los primeros intentos de establecer industrias fracasaron o fueron de escasa importancia debido al vacío que creó la falta de manufacturas británicas, pero a partir de 1840 se fue afianzando la industria casera.

La transformación del capitalismo mercantil a un capitalismo industrial se acentuó con la Guerra de Secesión (186l-65). Desde luego, las necesidades militares $y$, más tarde el afán por reconstruir el país, impusieron la necesidad de una industrialización masiva. En su afán por impulsar este proceso, el Presidente Abraham Lincoln eliminó las restricciones que afectaban la producción de algodón, carbón, hierro y objetos manufacturados en general. Durante el período de reconstrucción iniciado por el Presidente Andrew Johnson, apareció una nueva burguesía, la cual fue capaz de desarrollar enormemente la industria (especialmente la industria pesada), gracias a que el mercado se encontraba protegido por aranceles. Además, la expansión industrial fue posible debido al avance en materia de infraestructura, especialmente transportes y continuo ingreso de inmigrantes, que permitia contar con mano de obra abundante y barata. Hacia 1880, la industria pesada ya estaba sólidamente establecida. Esta fue la época de los Carnegie, Picrpont, Rockefeller y Vanderbilt.

A principios de este siglo (cuando Estados Unidos se pone a la cabeza de la producción agrícola e industrial mundial) se produce la fusión del capitalismo industrial con el capitalismo financiero. En efecto, el auge del industrialismo promovió la formación de un gran movimiento de capitales, fenómeno que influiria decisivamente en la orientación del crecimiento económico norteamericano y en los postulados económicos y políticos de Estados Unidos. Este movimiento de capitales de grandes proporciones condujo al expansionismo norteamericano en el exterior y produjo un decrecimiento del aislacionismo estadounidense (para una interesante discusión acerca de los verdaderos alcances del aislacionismo norteamericano; véase: James Chace: America's New Strategy of Gontainment. En: Harper's. Enero, 1978. Pp. 46-54). Desde que empezara este expansionismo, la principal área de acción fue América Latina; actitud que concordaba con las doctrinas Monroe $y$ otras posteriores formuladas por Estados Unidos respecto a este continente.

A fines de la Primera Guerra Mundial, la mitad de todas las inversiones extranjeras estadounidenses estaba concentrada en América Latina (Abraham F. Lowenthal: The United States and Latin America; Ending the Hegemonic Presumption. Op. cit. P. 202). A partir de 1930, empieza la penetración de los "conglomerados" norteamericanos en las industrias manufactureras latinoamericanas, atrayendo especial atención las de productos químicos, caucho, y mon- 
nen muy presentes el pasado de intervenciones militares y políticas, paternalismo, y explotación e injusticias económicas. He aquí el peso de la historia que lo llevan muy en los hombros y en la memoria los pueblos latinoamericanos. Así, Carter o cualquier presidente norteamericano que honestamente quiera cambiar la naturaleza de las relaciones interamericanas, se encuentra en la incómoda posición del hidalgo manchego, quien, al final de sus días, tuvo duro trabajo en convencer al cura, bachiller y barbero que había vuelto en juicio ${ }^{3}$. La literatura hispanoamericana es el mejor reflejo de la forma en que ese pasado se percibe como parte del presente ${ }^{4}$.

taje y accesorios dc automóviles. Entre la Primera y Scgunda Guerra Mundia! imperó cl sistema de inversión extranjera indirecta en tberoamérica.

La ayuda de Estados Unidos a csc continente comenzó en pequefía escala en 1938, fecha en la cual el "Export-Import Bank" otorgó, por un periodo de dos años, préstamos cercanos a 200 millonies de dólares a los gobicrnos de la región. La asistencia técnica se inició en 1942. En el decenio de 1940, el comercio latinoamericano con Estados Unidos aumentó considerablemente.

Entre 1946 y 1951 , el capital norteamericano en el continente ascendió a 1.629 millones de dólares y los beneficios de esa inversión se han calculado en 3.078 millones de dólares (Adolf Berle: Latin America; Diplomacy and Reality. New York, Harper \& Row, 1962).

La inversión directa norteamericana se ha dirigido preferentemente a desarrollar la industria del petróleo; y venczuela ha sido cl pais que mayor capital ha recibiclo por este concepto. Entre las medidas que han colaborado al auge de las invers'ones directas estadounidenses entre 1945 y 1960 se debe destacar el "The United States Economic Cooperation Act" (1948), la cual pone a salvo a los inversionistas de expropiaciones y riesgos derivados de la conver. tibilidad de la moneda.

Las décadas de 1960 y 1970 señalan la dominación económica de América Latina por parte de las empresas transnacionales, especialmente aquellas dominaclas por capital norteamericano. Esta ctapa coincide con las medidas más duras adoptaclas por los gobiernos ibcroamericanos hacia la inversión extranjera; por cjemplo, las tomadas por los gobiemos de Velasco Alvarado en Perú $y$ Allende en Chile, y la Decisión 24 del Pacto Andino.

${ }^{3} \mathrm{La}$ imagen es adecuada porque Estados Unidos debería convencer a los tres sectores más importantes en las sociedades iberoamericanas: Ia IgIesia Católica, los intelectuales y obreros.

En los últimos años, la actitud de ciertos sectores del clero latinoamericano hacia Estados Unidos se debe en gran parte a la influencia de la "teología de la liberación", un término inventado seguramente por Gustavo Gutiérrez, de la Pontificia Universidad Católica de Lima y que da título a una de sus obras publicadas en Lima por la Editorial Universitaria en 1971.

La "teología de la liberación" debe ser vista como una continuidad histórica (le los especiales problemas que ha debido enfrentar la Iglesia Católica en América Latina, los que ya se prescntaron en el siglo dieciscis (con respecto a este liltimo punto, véase: Edwin Edward Sylvest: Motifs of Franciscan Mission Theory in 16th Century New Spain Province of the New Gospel. Washington, Acatlemy of Amer:can Franciscan History, 1975).

- En electo, la literatura muestra, a lo largo de todo este siglo, numerosas obras que expresan este fenómeno. La lista cs inacabable y soblo con fines ilustrativos se ser̃alan algunos autores. Desde luego, la Revolución Mexicana en- 
Autores como Horowitz ${ }^{5}$ afirman que las acusaciones contra Estados Unidos no se basan tanto en políticas específicas sino que en el poder que éste posee y que así se explicaría la hostilidad de Cuba hacia China o de Rodesia hacia Inglaterra. En otras palabras, esta "teoría de la envidia" señala que mientras existan superpotencias, siempre habrá resentimiento motivado por el poder y la riqueza. Sin embargo, Japón y Alemania tienen actualmente grandes intereses económicos en la región ${ }^{6}$ y estos países no son vistos con los mismos

trega una pléyade de escritores en esta línea (una nómina de estos autores se encuentra en: Max Aub: Guta de Narradores de la Revolución Mexicana. México, Fondo de Cultura Económica, 1969, entre los cuales destacan Mariano Azuela ("Los de Abajo", "Nueva Burguesta") y Martín Lais Guzmán ("El Aguila y la Serpiente", "La Sombra del Caudillo"). Entre los norclistas hispanoamericanos tenemos a Miguel Angel Asturias ("La Mulata Tal", "El Señor Presidente"), Alejo Carpentier ("El Reino de este Mundo", "El Siglo de las Luces"), Roberto Fernández Retamar ("Epitalio de un Invasor"), Carlos Fuentes ("La Palabra Enemiga"), Gabrie! Garcia Márquez ("Cien Años de Soledad"), Nicomedes Guzmán ("Los Hombres Oscuros"), Augusto Roa Bastos ("Hijo de Hombre"), Volodia Teitelboim ("Hijo del Salitre", "Pisagua") y Mario Vargas Llosa ("Conversación en la Catedral"). Entre los cuentistas se puede nombrar a Julio Cortizar ("El Perseguidor") y Mario Vargas Llosa ("Los Jefes"). En el cuiento chileno (v'́ase: Yerko Moretić: El Nuevo Cuento Realista Chileno. Santiago, Editorial Universitaria, 1962) se pucden mencionar a Carlos Ossa ("Las Manos de Clemente Güemes"), Jaime Valdivieso ("La Espera"), José Migucl Varas ("La Denuncia"), Luis Vulliamy ("Joseluén"), Manuel Ro-jas ("Poco Sucldo"), Baldomero Lillo ("Subterra"). En el ensayo destaca José Carlos Mariátegui (revista "Amauta"). Desde los tiempos de José Martí, la poesía cuenta con un sinnumero de autores preocupados del imperialismo, por ejemplo, Ernesto Cardenal ("La Oración por Marilyn Monroe", "Los Salmos"), Pablo De Rokha ("La República Asesinada", "Yankilandia"), Nicolás Guillén ("Puerto Rico"). Desde su poema "Explico Algunas Cosas" de la Tercera Residencia, Pablo Neruda se transforma política y socialmente como se aprecia en la interpretación de la independencia americana en su "Canto General" y en obras de protesta como "Las Oligarquás". Respecto a la "poesía comprometida" chilena, véase: Luis Enrique Délano $\gamma$ Jorge Palacios: Antologia de la Poesia Social de Chile. Santiago, Editorial Austral, ?. La litcratura de protesta nace en Chile con la inquictud por la situación en las salitreras (véase: Yerko Moretić: El Relato de la Pampa Salitrera. Santiago, Ediciones del Litoral, 1962), y muchos de sus exponentes adhieren al marxismo.

- Irving Louis Horowitz: U.S Policies and Latin American Realities; Neighborliness, Partnership and Patemalism. En: Latin America; The Search for a New International Role (Ronald G. Hellman y Jon Rosenbaum, editores). New York, Sage Publications, 1975. P. 48.

- Entre $1965 y^{\prime} 1971$, estos dos países han triplicado, en comparación con Es. tados Unidos, sus inversiones extranjeras (vease: United Nations, Department of Economic and Social Affairs: Multinational Corporations in World Develop.ment. New York, Praeger Publishers, 1973. P. 157, tabla No 10). Se ha estimado que hacia 1978 Japón será el mayor inversionista privado en Brasil (Richard 'J. Barnet y Ronald E. Muller: Global Reach. New York, Simon \& Schuster, 1974. Pp. I96-197. Para las ventajas negociadoras que Japón tiene sobre Estados Unidos en Brasil, véase: Id. Pp. 202-203). 
ojos por los iberoamericanos. La diferencia está escrita por la historia y el comportamiento presente, porque es muy distinto tratar con Japón (país que ha buscado alcjarse de los asuntos internos latinoamericanos) que con Estados Unidos, el cual tradicionalmente ha conșiderado a América Latina como su "backyard". Inglaterra ofrece un buen caso de comparación en este respecto porque hasta comienzos de este siglo fue el mayor inversionista extranjero en América Latina. En efecto, a pesar de la explotación económica ejercida por los ingleses en América Latina, éstos no mostraron el mismo grado de violencia 8 exhibido por los norteamericanos, lo cual permite dar una mejor bienvenida a la inversión británica.

¿Cuál ha sido el carácter que en el pasado han tenido las relaciones interamericanas? He aquí unos pocos ejemplos. Sólo entre 1894 y 1924 Estados Unidos intervino militarmente veintiuna veces en América Latina. De las cincuenta ocasiones en las cuales ese país envió tropas fuera de Norteamérica en el siglo pasado, cuarenta y tres expediciones se despacharon hacia Iberoamérica ${ }^{9}$. Versiones más mo-

- Para un estudio de las inversiones británicas en América Latina, véase el exhaustivo cstudio de J. Fred Rippy: British Investments in Latin America; 1822-1949. Hamden (Connecticut), Archon Books, 1966.

a A partir de la expedición de Francis Drake, el Reino Unido tuwo interés comcrcial y militar por América Latina. Ya en el siglo XVI aparecen corsarios y piratas ingleses y flamencos merodeando por las costas de la región, En 1797 el Almirantazgo británico acordó en la necesidad de apoderarse de la zona ubicada al sur de Valdivia y de todo el cono meridional americano. Este proyecto fue deferido hasta 1806 , año en el cual el estallido de una nueva guerra cntre España e Inglatcra permitió que los ingleses invadieran Buenos Aires, de donde fucron expulsados en julio de 180\%. Se dejó para mejor oportunidad la idea de ocupar Chile, En 1825 se registra una nueva expedición británica (esta vez en compañía de los franceses) en el Rio de la Plata. Otras aventuras ingiesas en la zona son la ocupación de las Islas Malvinas en 1833 (en 1774 el Rcino Unido las había mantenido temporalmente), la excursión inglesa-española-francesa contra México en 1862 y la anexión de Bélice en 1869.

* Las intervenciones estadounidenses en América Latina se pueden clasificar en estratégicas, politicas $y$ financieras. Las intervenciones estratégicas se realizaron principalmente en la zona del Caribe y obedecieron a la política de expansión territorial nortcamericana. Algunas revistieron la forma de una anexión lisa y llana, como en Puerto Rico (tratado de París del 10 de diciembre de 1898), y otras establecicron un control público como en Cuba (enmienda Platt del 12 te junio de 1901 y tratado del 22 de mayo de 1903 , substituido por el del 29 de mayo de 1934) y Panamá (tratado Hay-Bunau-Varilia del 18 de diciembre de 1903). Las intervencioncs politicas, que comprendian la defensa de intereses económicos, fueron la consecuencia de la politica del "Big Stick" que el Presidente Theodore Roosevelt formulara en su mensaje del 4 de diciembre de 1904: "Hablad con suavidad, pero llevad una tranca c irćis lejos". Esta teoría fue especialmente aplicada, además de Roosevelt (1901-09), por William Howard Taft (1909-13) y' Calvin Coolidge (1923-29). Lugares predilectos fueron América Central (en Nicaragua en 1909, 1912 y 1928) y El Caribe (en Cuba entre 1906 y 1916). Esta política del "Gunboat Diplomacy" fue descartada a partir del "memorándum Clark" (17 de diciembre de 1928), pero, ha sobrevivido 
dernas son las intervenciones en la República Dominicana en 1965 , donde desembarcaron más de 22.000 "marines", y en los asuntos internos de Chile entre 1963-73 ${ }^{10}$. Muchos comentaristas creen que esta etapa de intervenciones ha terminado definitivamente; pero es necesario cuidarse de optimismos: en i1928 y 1966 también se decía lo mismo. En el plano económico, los "préstamos atados", que condicionan el otorgamiento de éstos a la compra de artículos estadounidenses o al empleo de transportes cle esa nacionalidad, han resultado un gran obstáculo al desarrollo de Iberoamérica ${ }^{11}$. La Alianza para

bajo diversas formas desde entonces. Las intervenciones financicras dieron lugar al fenómeno conocido como "Dollar Diplomacy". A través de esta política se ha pretendido proteger las inversiones privadas estadounidenses estableciéndose un control financiero. Tal ocurrió en forma limitada en Fondiras (tratado del 10 de enero de 1911) y Nicaragua (tratado del 6 de jumio de 1911); en estos dos casos súlo se acordó una fiscalización aduanera. La intervención más profuncla tavo luggar en la República Dominicana (tratado del 20 de enero y 7 de febrero de 1905, y 8 de febrero de 1507) y Haiti (tratado del 16 de septiembre de 1915). La intervención en la República Dominicana terminó en 1941 y en Hait en la segunda mitad de este siglo (en Haiti este control fue reforzado con ocupación militar hasta los acuerdos del 5 de agosto de 1.931 y 7 de agosto de 1933).

20 V'́ase: U.S. Senate, Staff Report of the Select Committee to Study Governmental Operations with Respect to Intelligence Activities: Covert Action in Chile, 1963-73. U.S Senate, 94th Congress, lst session (18 de diciembre de 1975).

1: En el caso de inversión directa, la exportación del pals inversionista está generalmente garantizada. En efecto, la agencia o sucursal promueve y se encarga de la venta de los productos de la casa matriz, $y$ eventualmente interviene en el proceso de fabricación, especialmente en caso que se puedan importar piezas que abaraten el costo total del artículo final. En camb:o, tratándose de inversión indirecta, no existe neccsariamente un aumento de las exportaciones del proveedor de capital. Por esta razón se han creado los "préstamos atados" "tied loans"). Este tipo de créditos han sido especialmente otorgados por cl "Export-Import Bank".

Los préstamos atados limitan la libertad económica del país importador de capital, impide una sana planificación en materia de inversiones y distorsiona el comercio internacional. Conforme a criterios clásicos de economia, este tipo de prácticas económicas resultaría a la larga desfavorable para el prestador porque las industrias favorecidas no serian capaces en el futuro de afrontar una competencia internacional; sin embargo, esta afirmación no es tan evidente en esta época del "post-mercado" creada por las operaciones de las empresas transnacionales, es decir, en esta era en la cual las subsidiarias y casa matriz transan entre si para aumentar las utilidades globales de la empresa transnacional y no conforme a la situación del mercacio.

Estos préstamos atados constituyei, en verdad, subvenciones solapadas a los productores y transportistas estadounidenses. En el Informe Rockefeller (véase Ja sección vi de este artículo) se aconseja al Presidente Nixon que suprima las condiciones a que quedan sujetos los programas de ayuda norteamericanos, en caso que interfieran con el proceso de desarrollo o menoscaben la sobcrania nacional de los patses latinoamericanos. Refiriéndose a la condición que se transporten las mercaderías en barcos de Estados Unidos, este documento scĩala: "Se ha estimado que esta exigencia reduce Ia efectividad de cada dólar de 
el Progreso, a pesar de toda la propaganda con que fue acompañada, no constituyó más que una versión moderna de paternalismo (por ejemplo, los gobiernos latinoamericanos turieron poco que decir en la administración de cste programa) y se basó en consideraciones estratégicas o en el miedo al "peligro rojo". En el pasado reciente, Estados Unidos ha bloqueado créditos a Bolivia, Chile y Guyana ${ }^{12}$. Para los fines de este artículo, basta con haber efectuado tan breve enumeración de hechos.

\section{I}

E1 peso de la historia no constituye el único elemento que obstaculiza un cambio radical en las relaciones interamericanas. También existen problemas estructurales. Descle luego, la opinión personal de Carter no es la única que cuenta en la dirección de la política exterior norteamericana. No me refiero al obvio problema del juego

asistencia de los Estados Unidos hasta un máximo de 20 centavos. Esta es una de las causas de mayor irritación para los paises en desarrollo... Cualquier subsidio que fuese necesario debicra ser dado ab'erta y directamente mediante una concesión de fondos del Congreso" (Texlo Oficial del Informe Rockefeller. En: El Informativo ALALc. Santiago No 360. 30 de diciembre de 1969. P. 20) .

La Comisión Especial de Coordinación Latinoamericana (CEcLA) cn su documento Consenso Latinoamericano de Tiña del Mar, aprobado el 17 de mayo de 1969 durante una reunión a nivel ministerial (véase su texto en: Vol. 1 Antario Chileno de Relaciones Internacionales, pp. 106-116, 1969), señaló: "Es indispensabic que la cooperación financiera externa no esté sujeta a condicio. nes que limitan la capacidad nacional para adoptar decisiones en cl campo de las politicas básicas dei país receptor" y, agregó: "Dcben suprimirse las dîsposiciones o criterios que ligan la utilización de préstamos a la adquisición de $b^{\dagger}$ enes y servicios en determinados países o descle determinados origenes" (punto No 28, letra e). Además, el Consenso Lalinoamericano de Viña del Mar condena en forma amplia todo tipo de condiciones a que se pretenda sujetar el financiamiento externo "por sus mutiliples cfectos negativos en la economía de América Latina" (punto Ne 29).

Lit Decisión 24 del Pacto Andino, no se refiere a los "préstamos atados", pero contiene normas que impiden determinadas condiciones en los contratos de tänsferencia de tecnologia o patentes (artículo 20), y en los contratos para la explotación de marcas de origen extranjero en los passes andinos (articulo 25).

12 Véase: Rafael Vargas Hidalgo: El Aplazamiento de Crédilos a Chile. En: El Mercurio. Santiago. 17 de agosto de $1971, \mathrm{p} .17$.

En junio de 1971, el Wrashington Post criticó al Subsecretario del Tesoro, John Connally, por haber bloqueado créclitos a Guyana y Bolivia en el Banco Mundial deb do a que estos páses no habian indennizato convenientemente a empresas norteamericanas expropiadas. En efecto, el representante de Estados Uniclos ante esta institución rechazó un préstamo a bajo interés y largo plazo destinado al desarrollo ganadero, luego que Bolivia nacionalizara la "International Processing Corporation" (cuyos bienes se estimaron entre 2 y 3 millones (le dolares); a pesar que la compensación correspondiente se encontralud en dis- 
entre los poderes ejecutivo y legislativo, sino que al fenómeno descrito por Theodore Lowi ${ }^{13}$. Este ha observado que a partir de la Segunda Guerra Mundial, los compromisos internacionales de Estados Unidos han estado siendo encomendados a diferentes departamentos gubernamentales y éstos a menudo comparten jurisdicción sobre algunas materias al mismo tiempo que gozan de cierta independencia legal entre sí. Esta estructura gubernamental impide una planificación eficaz de la política exterior. Asimismo, los autores de la "teoría burocrática" ${ }^{14}$ (quienes han llegado a conclusiones semejantes a las de Lowi, pero sin basarse como éste en un análisis filosófico sobre la naturaleza de la doctrina liberal) han demostrado que cada departamento de la administración pública defiende sus propios intereses y ejerce grandes presiones sobre el Presidente con el objeto de hacerlos prevalecer.

En consecuencia, la política de Carter hacia Iberoamérica se ve limitada por la acción de, entre otros, el Departamento de Defensa, el Departamento de Estado, el Departamento del Tesoro, el Departamento de Agricultura, la Agencia para el Desarrollo Internacional, etc. Esta afirmación se comprueba con una ilustración. En junio de 1976, el entonces canciller Kissinger afirmó ante la reunión de la Asamblea General de la Organización de Estados Americanos (OEA) que era necesario respetar el tope establecido por el Congreso de Estados Unidos a la ayuda destinada a Chile debido a las violaciones que este pais cometía a los derechos humanos. En los mismos momentos en que Kissinger pronunciaba estas palabras, los Departamentos de Estado y del Tesoro presionaban sobre el Senado para que éste aumentara el límite fijado por la Cámara de Diputados a

cusión. El bloquco de crćditos a Guyana se refirió a un préstamo por 5,4 millones de dólares, solicitado para la construcción de diques.

$\mathrm{Si}$ b:en es cierto que las instituciones financieras son libres de conceder o rechazar créditos, la situación es muy diversa cuando se adopta una actitud u otra como parte de un plan político concertado de antemano destinado a inmiscuirse en los asuntos internos de una nación.

13 The End of Liberalism. New York, W. W. Norton, 1969.

14 Con respecto a la "teoria burocrática", véase por ejemplo: Graham Allison: Conceptual Models and the Guban Missile Crisis. En: American Political Science Review (septiembre de 1969); Graham Allison; The Essence of Decision; Graham Allison y Morton Halperin: Burcaucratic Politics; A Paradigm and Some Policy Implications, En: World Politics (primavera de 1972); Robert Art: Bureaucratic Polilics and American Foreign Policy; A Critique. En: Vol. 4 Policy Sciences (1973); I.M. Destler: Presidents, Bureaucratic and Foreign Policy; Morton Halperin; Bureaucratic Politics and Foreign Policy; Stephen Krasner: Are Bureaucracies Important? En: Vol. 7 Foreign Policy (vcrano de 1972); Charles Lidblom: The Science of Muddling Through; James Thompson: On the Making of U.S. China Policy, 1961-1969; A Study in Bureaucratic Politics. En: China Quarterly (1962). 
las cantidades que Chile tendría derecho por concepto de asistencia económica para el año fiscal $1977^{15}$.

Además, existe otro actor que es capaz de ejercer mayor influencia que muchos departamentos burocráticos: las empresas transnacionales. Sobre esta materia existen numerosos antecedentss, por ejemplo, los intereses de las grandes compañías norteamericanas del petróleo hicieron fracasar la "Política de Buena Vecindad" en México; a comienzos de la década de 1960, las presiones de la International Telephone and Telegraph, ITT (que corría el peligro de ser expropiada) motivó la tensión que caracterizó las relaciones de Estados Unidos con Brasil 16; Anaconda y Kennecott determinaron en gran medida las acciones de Estados Unidos contra el gobierno de Allende, a pesar que la nacionalización del cobre fue aceptada por la unanimidad de los parlamentarios chilenos ${ }^{17}$.

Richard Nixon creyó que la promoción del desarrollo en Iberoamérica se debía hacer a través de las empresas norteamericanas que actuaban en la zona ${ }^{18}$. Esta política permitió que las compañías transnacionales aumentaran su influencia en el continente.

Existen otros factores estructurales del sistema político estadounidense que dificultan la labor de Carter en materia de política internacional. Desde luego, la escasa comunicación que tradicionalmente ha existido entre los candidatos presidenciales y sus partidos ha llegado a su extremo máximo en el caso de Carter, quien fuera un desconocido hasta hace pocos meses, incluso para sus correligionarios. Este hecho ha dificultado a las cancillerías iberoamericanas, como a las del resto del mundo, conocer qué se propone este nuevo mandatario y cuál es la mejor manera de tratar con él. Por otra parte, debido al carácter del sistema electoral estadounidense, la política internacional se paralizó, aun en materias críticas como las negociaciones sobre limitación del armamento estratégico ("sALt talks"), durante los dieciocho meses que precedieron a las elecciones: tal como ha sucedido en el pasado, el resultado ha sido una avalancha de pro-

${ }^{15}$ Commission on United States-Latin American Relations: The United States and Latin America: Next Steps. New York, Center for Inter-American Relations, 20 de diciembre de 1976, p. 7.

${ }^{10}$ En 1964, al ser depucsto João Goulart, Estados Unidos envió felicitaciones oficiales a los militares brasileños casi antes que éstos se hicieran cargo del poder.

${ }^{17}$ Es un error decir que Allende nacionalizó esa industria porque éste no tenía poder para ello, sino el Congreso. Además, esta medida se adoptó por unanimidad y por parlamentarios de diversas tendencias políticas. Por otra parte, este paso ya había sido preparado durante el gobierno anterior.

${ }^{18}$ Para una discusión de esta política de Nixon, véase: Irving Louis Horowitz: U.S. Policies and Latin American Realities: Neighborliness, Partnership and Paternalism. Op. Cit., p. 46. 
blemas sobre el escritorio del presidente, al dia siguiente de la transmisión del manclo.

\section{I I}

Aquí entramos al estudio de las características generales que hasta el momento muestra la politica internacional de Carter $y^{\prime}$ que se refleja en las relaciones de Estados Unidos con Iberoamérica.

Actualmente se nota en la Casa Blanca un mal que ya es endémico en Estados Unidos: el presidente carece de experiencia en materia internacional. Pero, a pesar de esta inexperiencia, Carter ha sabiclo defender ciertos principios fundamentales. Entre éstos destacan los derechos humanos, cuya protección, independientemente del valor personal que Carter les dé, constituye una inteligente actitud política interna en un país que viene saliendo del escándalo Watergate y de las revelaciones acerca de los métodos empleados por Kissinger. En efecto, Watergate demostró los peligros que tiene el sistema liberal de gobierno; y' Carter, a través de su defensa de los derechos humanos, reafirma el credo liberal. Por otra parte, el más importante objetivo de Kissinger fue mantener la estabilidad clel sistema internacional, aun a costa de violar principios morales o no prestar atención al problema de los derechos humanos ${ }^{19}$, así, poniendo énfasis en la defensa de estos derechos, Carter logra que la opinión pública lo clistinga del ex Canciller.

Al igual que en las presidencias anteriores, ahora falta una clara definición del interés nacional cle Estados Unidos en sus relaciones internacionales. Esta definición se hace más difícil considerando la estructura política y burocrática de este país y el continuo aumento de poder de las empresas transnacionales norteamericanas. ¿Se seguirá pensando que "What is good for General Motors is good for the United States"?.

No bastaría con que Carter tuviera nobles principios de política exterior porque el éxito de ésta también clepende de la estrategia que se adopte (es decir, de la manera como se relacionan los diversos objetivos entre sí), la ejecución práctica cle aquellos ideales y el mantenimiento del apoyo interno a esos postulados. Y es precisamente en estas materias doncie Carter se muestra más débil. Descle luego, este presidente ha tratado de contrarrestar su inexperiencia abordando los problemas de una manera que pretende ser "técnica", a pesar de

10 Véase: Richard A. Falk: Whal's Wrong with Henry Kissinger's Foreign Policy? Princeton University, Center of International Studics, julio de 1974 (Policy Memorandum No 39), pp. 17-18, 26, 30.

Carter comenzó a referirse al problema de los derechos humanos, bajo la presión đel Congreso norteamericano, en la reunión de la Organización de EsLados Americanos en Santiago de Chile (1976). 
la clara naturaleza política que generalmente éstos tienen. Además, Carter ha mostrado un optinismo ingento ante los problemas internacionales, hecho que también se cleriva de su inexperiencia. Asimismo, Carter ha tendido a despreciar los distintos matices de los problemas internacionales. Por otra parte, éste no ha sabido establecer claramente las prioridades de sus objetivos internacionales. Todos estos defectos han determinado una mayor participación del Congreso norteamericano en la conducción de la política internacional de Estados Unidos. En consecuencia, los observadores de las relaciones interamericanas deben prestar atención no sólo al pensamiento de Carter sino que también al de los parlamentarios más influyentes. En este contex to se debe comprender, por ejemplo, el incidente, un tanto tragicómico ocurrido durante el discurso pronunciado el 17 de febrero de 1977 por el Presiclente de México, José López Portillo, ante el Congreso de Estados Unidos. La única ovación que entonces se escuchó fue cuando éste señaló que "los problemas de México han de ser solucionados por México" ".

Si se miran las relaciones interamericanas descle la perspectiva de Estados Unidos, éstas deben ser comprendidas dentro del contexto de los problemas más graves que este pais enfrenta en otras regiones del mundo: la situación en el Cercano Oriente, proliferación de armas nucleares, "SALT talks", venta de armamento, repercusiones internacionales de la crisis de la energía.

\section{IV}

Ahora nos abocamos al estudio del contenido de la política de Carter hacia Iberoamérica. Nace aqui una primera pregunta: ¿qué entenclemos por tal?

Se puede alegar que en el pasado no ha existido una politica norteamericana hacia América Latina si con ello significamos una definición del interés nacional de Estados Unidos en el área: la formulación de postulados y establecimiento de mecanismos que interpreten este interés; aplicación de estos postulados y mecanismos conforme a un escudio minucioso de la situación en cada país latinoamericano y de acuerdo a una diferenciaçión de las particularidades políticas, económicas y culturales de estos estados; y la coordinación de la posición estadounidense en los diversos países iberoamericanos con el objeto de alcanzar el interés nacional en la zona. Es en este sentido que George Kenan, organizador y' primer clirector del "Po. licy Planning Staff" del Departamento de Estado, ha dicho que, so.

${ }^{n}$ Véase el texto de este discurso en: The New York Times. 18 de febrero de 1977, p. I4. 
bre todo hasta la Segunda Guerra Mundial, Estados Unidos ha carecido de una política hacia América Latina 2 .

Examinando los elementos enunciados en el párrafo anterior, surge una importante observación. Tradicionalmentese se habla de América Latina como si fuera una sola entidad, casi monolítica. Sin embargo, América Latina no existe, salvo en el mapa; es decir, se trata de un concepto geográfico y no cultural, político o económico. En un espacio varias veces superior a Europa, conviven paises con el poder económico de Brasii y la pobreza de Guatemala; Chile, que posee una de las tasas más altas de alfabetismo en el mundo ${ }^{22}$, tiene por vecino a Bolivia, que bate el récord opuesto ${ }^{23}$; la población predominantemente europea de Uruguay tiene escasa relación cultural con los indígenas de Honduras; las experiencias políticas de México no admiten parangón con las de Argentina. Lo que une a América Latina es el idioma común ${ }^{24}$ y una enorme simpatía a nivel de pueblos, la cual ha nacido a través de tres condiciones históricas: pasado común bajo el poder español, lucha por la independencia nacional producida en una misma época (gesta que motivó los primeros contactos y colaboración militar iberoamericana) y experiencia común bajo el imperialismo político y económico de Estados Unidos. Este último elemento permite comprender por qué los países latinoamericanos se muestran más unidos que de costumbre cuando se trata de hablar con el vecino del norte

Considerando este factor, se puede afirmar que Carter tendria una gran ventaja si careciera cle una politica global hacia América Latina destinada a aplicarse en la misma furma e intensidad en todos los rincones del continente. A juzgar por las declaraciones hechas a este autor por Robert Pastor, experto sobre América Latina en el National Security Council (consejo superior que asesora al presidente norteamericano en materia de seguridad nacional)', en la presente administración existe preocupación por distinguir las peculiaridades de cada país iberoamericano en la formulación de la política exterior. Así, en su discurso ante la oeA del 14 de abril recién pasado, Carter señaló: “. . . a single U.S. policy to Latin America and the Caribbean makes little sense. What we need is a wider and

21 Vease el prefacio de su obra: American Diplomacy; 1900-1950. New York, Mentor Books, 1963. 12ạ edición.

ma 90 por ciento de alfabetismo. Adcmás, es el séptimo pais en el mundo con la mayor tasa de población en edad cscolar matriculada en un establecimiento de enser̃anza. Para estas cifras véase: World Military and Social Expenditures (Ruth Leger Sivard, editora). Virginia, 1977.

$\approx 45$ por ciento de alfabetismo. Fuente: Id.

2 Fuera de la obvia excepción de Brasil, Guyanas y regiones del Caribe, existen vastas comunidades indigenas donde no se habla español, un caso importante es Bolivia. 
more flexible approach worked out in consultation with you. Together we will develop policies more suited to each nation's variety and potential" 25. Estas palabras no han sido unánimemente bien recibidas en América Latina, así, por ejemplo, el canciller peruano, José de la Puente, expresó que Estados Unidos también debe negociar con América Latina como un todo.

Ahora bien, se puede afirmar que en el pasado Estados Uniclos ha poseído una política hacia América Latina si por tal sólo entenclemos una actitud general o una postura vaga que se traduce en la persecución de ciertos objetivos específicos.

Aún es temprano para determinar si acaso la "política" de Carter hacia Iberoamérica cae dentro de alguna de las dos acepciones que tiene la expresión y que se han examinado arriba.

El hecho que Carter pertenezca al Partido Demócrata no constituye, contrariamente a lo que otros autores han argüido ${ }^{20}$, un ele-

25 Véase el texto de este discurso en: The New York Times. 15 de febrero de 1977 , p. 10.

29 Osvaldo Sunkel: Esperando a Godot; América Latina ante la Nueva Adr ministración Republicana de los Estados Unidos. En: Estudios Internacionales (Universidad de Chile) (abril-junio 1969).

De acuerdo con Sunkel, en las administraciones demócratas se formularian programas globales y de gran alcance, los que se diseñan conforme a los intereses nacionales a largo plazo. Los gobienos republicanos, en cambio, auspiciarían una política que se adecúa a consideraciones tácticas inmediatas y a situaciones específicas; por tanto, estas administraciones preferirían las negociaciones bilaterales con países latinoamericanos.

Esta teoría podria predicarse en alguna medida a los gobicrnos de Franklin Roosevelt (1933-45) y John Kennedy (1961-63), quienes formularon, respectivamente, la Politica del Buen Vecino y la Alianza para el P'rogreso; y a algunos gobiernos republicanos. Sin embargo, las excepciones demuestran las debilidades de esta doctrina, por ejemplo, los presidentes demúcratas Harry Truman (194553) y Lyndon Johnson (1963.69) no adoptaron programas semejantes a los de Roosevelt y Kennedy; y en la administración republicana de Dwight Eisenhower (1953-61) se trató de implementar un plan global de ayuda social como una manera de evitar la repetición de los acontccimientos cubanos.

Hay otros aspectos de la teorfa de Sunkel que también son poco convincentes. Alega este autor que en los gobiemos republicanos los criterios generales se desprenden de la acción efectival que éstos desarrollan y no constan en declaraciones o documentos, o bien, éstos están redactados en términos vagos $y$ sólo poseen un contenido superficial. En las administraciones demócratas, los intereses particulares $y$ de corto plazo se deberían acomodar al programa nacional que se pretende llevar a cabo; esta caracteristica explicaria la mayor intervención que tien'en estos gobiemos en América Latina. IEn cambio, en los regímenes republicanos, las empresas privadas estadounidenses estarian llamadas a ocupar una posición más importante en el continente americano. De esta última circunstancia resultaría otra diferencia: los demócratas estarían más deseosos que el estado armonizara los intereses nacionales con los privados en América Latina, porque ambos no siempre coinciden; y los republicanos afirmarían que el estado no debe interferir en las actividades de los particulares porque aquellos intereses se identifican mutuamente. 
mento suficiente para determinar las características de su política exterior.

Durante su recience campaña electoral, Carter no dedicó especial atención a América Latina, salvo en sus referencias acerca de los derechos humanos ${ }^{27}$. En este sentido, Carter se pareció más a Nixon ${ }^{2 s}$.

m En esta materia, cl caso de Chile cstuwo siempre presente en la boca del candidato demócrata. Carter sc refirió insistentemente a este pais durante su debate televisado con Ford.

as El 28 de encro de 1969, sólo una vez. instalado en el poder, Nixon encargó a Nelson Rockefeller que efectuara a la brevedad un informe sobre Latino. américa. Este Informe Rockefeller, cuyas recomendaciones se basan en la importancia miliar y politica de Iberoamérica, fue evacuado el 30 de agosto de 1969 , itego que el viaje de Rockefeller a este continente ocasionara graves problemas policiales, polfticos y diplomáticos. Nixon no prestó atención a las conclusiones mis plausibles de este informe, por ejemplo: a) Estados Unidos debería apoyar las organizaciones regionales latinoamericanas como el Grupo Andino y el Mer. cado Común Centroamericano; b) el aumento de las exportaciones iberoamericanas permitirian a América Latina financiar sus cxportacioncs; asi, Estados Un dos deberia revisar sus tarifas arancelarias y duplicar en 1976 su intercambio comercial con el continente; c) suprimir los "prestamos atados"; d) terminar con las represalias polfticas que se toman al momento de clecidirse la concesión de un crédito; e) otorgamiento de empréstitos a bajo interćs, de 3 a 5 años, para financiar proyectos en los campos de la agricultura, educación pública $y$ desarrollo urbano; f) posecr funcionarios estadounidenses capaces de negociar $y^{\prime}$ towar decisiones con celeridad y efectividad en materia de relaciones interamericanas; g) evitar la confusión entre operaciones de empresas privadas norteamericanas y administración de programas públicos de ayuda; h) uniformar las normas estadounidenses que rigen las inversiones privadas en el cxterior; $c$ i) coopcrar con los bancos de desarrollo (nacionales o regionales) con el objeto de aumentar los ahorros locales e invertirlos productivamente.

La inutilidad práctica de estas recomendaciones se demuestra con estos ejemplos: bloqueo de créditos a Bolivia, Chite y Guyana; concesión de créditos atados; represalias cconómicas contra los gubiernos de Chile y perú; imposición, en agosto de 1971, de un gravamen del 10 por ciento a todas las importaciones norteamericanas como resultado a la polftica económica adoptada por Estados Unidos ("Phase I"); resolución del 29 de octubre de 1971 del Congreso norteamericano que puso término al programa de ayuda al extranjero.

En la elección presidencial de 1972, tanto el candidato demócrata, George McGovern, como el republicano, Richard Nixon, mostraron escaso interés por las relaciones interamericanas; salvo la preocupación por Cuba, que siempre está en la mente del elcctorado norteamericano. Durante esta elección, McGovern demoró la publicación clel Informe Stephansky, que resumiría su posición hacia Ibcroamérica, y Nixon insistió que su gobierno perseguiria una po. lítica de "Asociación Madura" ("Mature Partnership") con América Latina, po. lítica que fucra definida por el entonces Secretario de Estado norteamericano, William Rogers, en estos términos: "Nuestra politica será de participación en el hemisferio $y$ de firme adherencia al s.stema interamericano; será una política de continuación de nuestros compromisos al progreso económico y social de América Latina, por medio del comercio, la inversión, la ayuda y a través de nuestras actitudes políticas; es una politica de respeto a la diversidad de nuestros estados nacionales y a la determinación de no permitir ningún vestigio de hegemonia en nuestras relaciones hemisféricas; es una politica que reconoce que Estados Unidos no tiene, ni deberia tener un monopolio sobre la iniciativa o 
que a Kennedy, quien hiciera de la Alianza para el Progreso uno de los grandes pilares de su programa presidencial. Pero el silencio de Nixon y el de Carter ticnen distintos motivos. El primero seguía la política cle Kissinger, quien, como ya se ha dicho, buscaba la estabiliclad internacional, lo cual le impulsaba a aumentar contactos con lás grandes potencias y desatenderse de los países más pequeños. En cambio, el mutismo de Carter perseguía no dar la impresión que patrocinaría una política paternalista hacia América Latina.

la responsabilidad; finalmente, es una politica que alienta la creciente participación de los paises latinoamericanos en los asuntos mundiales y el creciente interés de otros paises por cooperar en forma productiva con América Latina".

Mientras se afinaba la existencia de una política de "Asociación Madura", estos hechos ocurrían. Estados Unidos promulgaba una ley de pesca que contemplaba sanciones económicas a las naciones que multaran barcos pesqueros norteamericanos que operaran sin licencia más allí de 12 millas de la costa (aguas que ese pais consideraba internacionales). Esta mediłla provocó, en noviembre tie 1972, las enérgicas protestas de Chile, Ecuador y Perú, paises que defendan su soberanía solsre 200 millas. Esta ley entró en vigor en los momentos en que se preparaba la Tercera Conferencia sobre el Derecho del Mar conio. cadla por las Naciones Unidas.

iEstas actitudes de Nixon fueron reconocidas en sit tiempo como un gran obstáculo a un mejor entendimiento entre las Américas. Así, algunos observadores propusieron la inmediata adopeión de las recomendaciones más laudables del Informe Rockefeller, otros, como el senador demócrata por Florida, Lawton Chiles, señaló la necesidad que Kissinger aloptara una nueva politica interamericana y visitara Iberoamérica. También se rumorcó la visita cle Nixon a este continente. Pero los remedios nunca legaron y el mal se agravó. Así, por cjemplo, las negociaciones entre Cuba y Estados Unidos sobre piratería aérea se estancaron $y$, en abril de 1973, Fidel Castro clausuró el "puente aéreo" que mantenfan cstos paises. Por otra parte, el 4 de abril de 1973 se inauguró Ia Tercera Asamblea General de la oL $\Lambda$, organismo que tiene entre sus objetivos principales impulsar la cooperación económica interamericana. Durante esta reunión Estados Unidos insistió en su polílica de "Asociación Madura", rechazó el Ievantamiento de la suspensión de Cuba como miembro de la ors, prometió mejorar las condiciones de su comercio exterior con la región y reiteró su posición respecto a un mar territorial de 12 millas. Etı esta misma época, micn. tras el Secretario de Estado William Rogers anunciaba un viaje a América Latinil, Estados Unidos proclamaba la venta de sus reservas de materias primas, Io cual molivó las protestas de Perú (5 de abril de 1973) porqucie esta medida perjudicaba a las cconomias latinoamericanas.

La tensión que las relaciones interamericanas tuvieron en este ticmpo se demuestra con la proposición hecha por Chile $y$ otros paises de excluir a Estados Unidos de la OEA al mismo ticmpo que se robustecía la Comisión Económica Coordinadora para América Latina (CECLA) y se aumentaba la independencia de la Conferencia Especializada para la Aplicación de la Ciencia y la Tecnología al Desarrollo de América Latina (CACTAL). CECLA y GAGraL scrian los instrumentos a través de los cuales se profundizaría el trato con otros países y entidades regionales. La propos:ción de Chile planteó un delicado problema de conveniencias porque as se perdería el contacto directo con Estados Unidos, en las Naciones Unidas la posición latinoamericana se confundiría con la del Tercer Mundo en general, y algunas instituciones como el Banco Interamerica- 
Carter careció de un grupo de trabajo encargado de aconsejarle especialmente sobre problemas latinoamericanos durante su campaña presidencial. Una vez electo, éste decidió adoptar extraoficialmente el Informe Linowitz como suyo. He aquí la inspiración de todas las acciones tomadas por Estados Unidos hacia Iberoamérica en 1977. Varias razones facilitaron este apadrinamiento del Informe Linowitz. Entre ellas se cuentan éstas: muchos de los miembros de la comisión que redactó este documento trabajaron intensamente por Carter durante la campaña electoral; este estudio tuvo, al momento de ser publicado, gran acogida por parte de importantes sectores, incluyendo un elogioso editorial del New York Times ${ }^{20}$; el Informe daba gran importancia a la defensa de los derechos humanos y se oponía a una relación paternalista con Iberoamérica; además, Sol Linowitz, principal redactor del documento, pertenecia a la "Trilateral Commission", un pequeño grupo privaclo, formado bajo la inspiración de David Rockefeller, del cual Carter ha escogido a la mayoría de sus asesores en politica internacional ${ }^{30}$. Por otra parte, la existencia de este estudio permitía la apicación de una política coherente y ahorraba la necesidad de encargar un estudio al comienzo de su administración (como ocurriera con el Informe Rockefeller ordenado por Nixon), Io cual crearía la impresión de una gran improvisación en la conducción de las relaciones interamericanas.

EI informe en discusión lleva el nombre de Sol Linowitz, presidente de la "Commission on U.S.-Latin American Relations", la cual redactara este estudio. Esta comisión ha sido creada con los auspicios del "Center for Inter-American Relations", una organización privada cuyo objeto es "estimular en Estados Unidos la comprensión de Ios demás pueblos del Hemisferio Occidental" y que tiene por fundador y presidente honorario a David Rockefeller (he aquí de nuevo la "Rockefeller connection").

Linowitz ha sido embajador ante la ofa (1966-69) y actualmente es socio principal de uno de los mayores estudios de abogados norteamericanos: "Coudert Brothers", el cual tiene oficinas en el exterior y que defiende los intereses de las grandes compañías norteamericanas. Linowitz ha desempeñado altas responsabilidades en empresas transnacionales como Xerox International.

no de Desarrollo desaparecerían o perderian su fucrza. En consecuencia, los miembros de la oEA adoptaron un proyecto presentado por Perú, y respaldado por paises como Venczuela, que creaba una comisión especial dedícada a elaborar un nuevo sistema interamericano que sea "operativo, realista y coherente".

208 de noviembre de 1974 .

" Acerca de la "Trilateral Commission", véase: The Boston Phoenix. Boston, 26 de julio de 1977, p. 18. 
Entre los demás componentes de la comisión que redactó este Informe se encuentran principalmente ${ }^{31}$ profesores universitarios ${ }^{32}$ y representantes de empresas con grandes intereses en la región ${ }^{33}$.

El Informe Linowitz ha aparecido en dos versiones. La primera fue elaborada en octubre de 1974 y fue publicada en mayo de 1975 en una obra que contiene varias monografías sobre problemas interamericanos ${ }^{34}$. La otra edición apareció el 20 de diciembre de 1976 con el título: "The United States and Latin America: Next Steps" 35. Esta nueva versión obedeció a la necesidad de acomodar los antiguos análisis a un programa de carácter presidencial. Considerando su mayor importancia política, este artículo sólo se refiere a esta última edición.

Las ideas sobre las cuales se funda el Informe Linowitz son Ias siguientes: se debe terminar con el paternalismo y la idea de la "relación especial" "3e que ha caracterizado las relaciones interamericanas por cerca de un siglo y medio; es necesario reafirmar el más absoluto respeto a la soberanía nacional de cada pais; América Latina no representa un peligro estratégico para la seguridad de los Estados Unidos y no se percibe ninguna amenaza seria, interna o externa, a la seguridad del Hemisferio Occidental; los problemas económicos son los más urgentes para los iberoamericanos, pero Estados Unidos debe examinarlos dentro de un contexto mundial sin necesidad de adoptar una política económica internacional especial para el continente americano; es necesario contar con la colaboración de América Latina si se quieren mejorar las relaciones interamericanas, lo cual supone cambiar la posición tradicional de Estados Unidos; la nueva administración norteamericana debería dar prioridad al mejoramiento de las

rt Entre los demás miembros de esta comisión se cuentan: George Harrar (Rockefeller Foundation), Thomas Messer (Solomon Guggenlzeim Museum) y Rita Hauser (estudio juridico "Stroock, Stroock y' Lavan").

32 Harrison Brown (California Institute of Technology), Albert Fishlow (Berkeley University), Richard Gardner (Columbia University), Alexander Heard (Vanderbilt University), Theodore Hesburgh (University of Notre Dame), Samuel Huntington (Harvard University), Gcorge Lodge (Harvard University), Arturo Morales-Carrión (Universidad de Puerto Rico), y. Clifton Wharton (Michigan State University).

${ }^{33}$ Michael Blumenthal (Bendix Corporation), Andrew Heiskell (Time Inc.), Lee Hills (Knight Newspapers, Inc.), Nicholas de B. Katzenbach (rBm Corporation); Charles Meyer (Sears, Roebuck \& Company), Peter Pecerson (Lehman Brothers) y Nathanicl Samuels (Louis Dreyfus Holding Company, Inc.).

"s The Americas in a Changing World; $A$ Report of the Commission on United States-Latin American Relations, New York, The New York Times Book Co., 1975.

3s The United States and Latin America: Nexl Steps; A Second Report by the Commission on United States-Latin American Relations.

30 La "special relationship" ha sido el eufemismo usado por los gobiernos y autores norteamericanos para referirse a la situación de dependencia en que se encuentra América Latina con respecto a Estados Unidos. 
relaciones interamericanas, lo cual permitiría un diálogo mús eficaz con todos los paises en desarrollo; se identifica el problema del Canal de Panamá como la materia más crítica en las actuales relaciones interamericanas.

El Informe Linowitz contiene veintiocho recomenclaciones que a continuación, y con el permiso y la paciencia del lector, se reproducen textualmente ${ }^{37}$ considerando su enorme importancia para comprender las futuras acciones de Estados Unidos:

1) La nueva acministración deberia declarar con prontitud su total respeto a la soberańa de cada nación latinoanericana, como asimismo, comprometerse a no llevar a cabo ninguna intervención militar unilateral o intervención encubierta en los asuntos internos de ano de estos países;

2) EI nuevo gobierno debería negociar rípidanente con Panamá un nuevo tratado sobre el Canal. Miembros de los partidos demócrata y republicano como del Senado $y$ la Cámara de Díputados, deberian participar en estas discusion'es. El P'residente debería señalar a la opin'ón pública de Estados Unidos por qué es deseable y urgente la adopción, en condiciones equitativas, de un nuevo tratado con Panamá;

3) La administración de Carter deberia cumplir cabalmente con las disposiciones legales que ordenan informes periódicos acerca de la forma como se protegen los derechos inamanos, y debería reforzar su capacidad interna con respecto a la evaluación de las supuestas violaciones a estos derechos ocurridas tanto en las Américas como en otros continentes. La responsabilidad de formular e implementar la política de Estados Uniclos respecto a la violación de los derechos humanos debería ser permanente y estar a cargo de una comis:ón a alto nivel dentro del gobicrno;

4) El gobierno de Estados Unidos deberia firmar y apoyar la ratificación de la Convención Americana sobre Derechos ITumanos y la Convención Internacional sobre Dercchos Civiles y Politicos;

5) El gobierno de Estados Unidos deberia apoyar los movimientos que pers guen reforzar la independencia, acceso y aumento de personal de los mecanismos regionales americanos dedicados a examinar la situación de los derechos humanos; especialmente la Comisión Interamericana sobre Derechos Humanos, la Comisión de Derechos Humanos de las Naciones Unidas y organizacion'es no gubernamentales que se dedican a estudiar violaciones a los derechos humanos;

6) Con el objeto de determinar si acaso algún gobierno está comprometido en violaciones evidentes y sistemáticas a los derechos humanos, Estados Unidos debería considerar los informes preparados por la Comisión sobre Derechos Humanos de las Naciones Unidas, la Comisión Interamericana sobre Derechos Humanos, e instituciones privadas como Cruz Roja Internacional, Comisión Internacional de Juristas y "Amnesty International". También se deberia tomar en cuenta el grado de coopera-

ST Traducción del autor.

Generalmente este tipo de textos aparecen en forma de aniexos en articulos y libros. Sin embargo, considerando que forma parte del derecho consuetudinario del lector: saltarse esos anexos, $y^{\prime}$ que estas reconendaciones son importantes para conocer la politica de Estados Unidos, he decidido arriesgarme a que la lectura termine aqui. 
ción que el gobicrno cuestionado preste a la investigación te esas organizaciones;

7) El gobicrno de Estados Unidos deberia aclarar su determinación de no conceder ayuda militar o vender equipo militar o policiaco a países que se determine que sus gobiernos o fuerzas de seguridad cometen violaciones sistemáticas y evidentes a los dercchos fundamentales. Tampoco el gobicrno de Estados Unidos debería poner a disposición de ningún país equipos los cuales se crea fundadamente que se pueden usar en la supresión de los derechos humanos;

8) Al provecer ayuda cconómica bilateral o asistencia a través de organizaciones multilaterales, Estados Unidos deberia evitar otorgar su apoyo a regimenes que sistcmática y claramente violan derechos humanos fundamentales. Deberla evitarse la adopción de medios de acción automáticos y absolutos, asimismo, los pueblos no deberian de sufrir las consecuencias de acciones efectuadas por sus gobicrnos; pero, al mismo tiempo, clando se otorgue ayuda destinada a los sectores más necesitados de la población, Estados Unidos no debería fomentar de ninguna manera medidas represivas o dejarse asociar con gobiernos que ejercen represiones brutales;

9) Estádos Uniclos debería considerar el uso de sus embajadas como lugares de refugio temporal por personas que huyen debido a su ejercicio de derechos civiles y políticos básicos; y deberfa facilitar sistemáticamente los procedimientos de inmigración a las víctimas de represión politica, independlentemente de la ideologia de éstas;

10) La nueva administración debería buscar modos de reabrir, gradual y recíprocamentc, el proceso de normalización de relaciones con Cuba,

Esta Comisión no puedic tener la presunción de ofrecer proyectos de negociación al gobicrno, pero recomienda que se emprenda una serie de acciones recíprocas, entre las cuales se cuenten éstas:

a) El Presidente debería afirmar la determinación del Gobierno de Estados Unitlos de usar su poder en la forma más amplia permitida por la ley, con el objeto de prevenir acciones terroristas contra Cuba o cualquier otro pais o contra ciudadanos estadounidenses, y arrestar y procesar a quienes cometen estas acciones. Esta Comisión espera que de esta manera Cuba evite la interrupción del acuerdo sobre sccuestros aćreos;

b) Lucgo, representantes de la administración de Carter deberian indicar a representantes cubanos que Estados Unidos está preparado para levantar el embargo de alimentos $y$ medicinas, $y$ entrar en una serie de negociaciones con Cuba, en las cuales sc examinen todos los problemas pendientes entre las partes. Esta acción de Estados Unidos debería ocurrir siempre que Cuba dé garantías satisfactorias que:

(1) está preparada para dar una respuesta pública, pronta y apropiacla (como, por ejemplo, la liberación de prisioneros estadounidenses) :

(2) sus tropas están siendo retiradas de Angola y se abstendrá de intervenir militarmente en otros lugares, $y$

(3) respetará el principio de autodeterminación y no intervención en cualquier Ingar y especialmente en Puerto Rico.

Una respuesta satisfactoria de Cuba podría conducir a negociaciones más importantes y amplias, que se deberian desarrollar en forma paulatina y con el objeto de efectuar concesiones reciprocas;

11) La nueva administración debería explorar y alentar a todo nivel 
(mundial, regional o subregional), que sea apropiado y posible, los esfuerzos hechos con el objeto de establecer acuerdos de limitación de armas convencionales entre paises proveedores y consumidores. Como una forma de prevenir el aumento de la carrera amamentista, la nuera administración deberfa tratar de negociar la armonización de los programas de venta de armas y políticas crediticins de las naciones provecdoras;

12) Es primordial que Estados Unidos ascgure que cualquicra de sus transferencias de tecnologia nuclear o material atómico a otras naciones dependa cie ia implementación de estrictas medidas de protección internacionales $y$ que esta tecnología sea provista preferencialmente a aque. llos estados que sean partes del Tratado de No Proliferación Nuclear. La nueva administración debería tratar de retardar la explotación de plantas nucleares reprocesadoras o enriquecedoras de material atómico. Asimismo, Estados Unidos debería alentar nuevas adhesiones al Tratado sobre Prohibición de Armas Nucleares en América Latina (1967) y considerar la elininación de sus objeciones al Protocolo Primero de esta convención. El nuevo gobierno deberia afirmar que consideraciones basadas en no proliferación nuclear consticuirí uno de los mayores factores en el discño de la polftica de Estados Unidos hacia el resto de las naciones;

13) A comienzos de 1977, Estados Unidos debería tomar la iniciativa en hacer estudiar la concesión inmediata de un aumento general al capital del Banco Mrundial, el cual permita satisfacer las necesidades de éste hasta mediados de 1980. Asimismo, Estados Unidos deberia apoyar un aumento continuo $\mathrm{y}$ significativo de las cantidades que el Banco Interamericano de Desarrollo destina a préstamos. Además, cl Congreso deberfa actuar con prontitud con el objeto que Estados Unidos cumpla sus compromisos contraldos con el Banco Mundial y el Banco Interamericano de Desarrollo;

14) Paulatinamente, Estados Unidos deberia terminar con su programa de ayuda bilateral hacia los paises de ingresos medios y concentrar sus esfuerzos en los estados más pobres;

15) El Congreso de Estados Unidos deberfa cumplir sus compromisos pendientes con la cuarta provisión de fondos de la "International Development Association", IDA, y los poderes ejecutivo $y$ legislativo deberian acordar inmediatamente la total participación de Estados Unidos en ia quinta provisión de fondos, de una manera tal, que se permita un aumento real de los recursos de inA;

16). El Presidente deberia encargar a un comitć coordinador a alto nivel dentro del gobierno de Estados Unidos, que conduzca exámenes periódicos y estructurales de los problemas relacionatos con todos los movim:entos de capital, privado $y$ público, en los países en desarrollo;

17) Estados Unidos deberia iniciar consultas con América Latina respecto a estrategias $y$ posiciones conjuntas en las Negociaciones Multilaterales de Comercio de Ginebra, con el objeto de:

(a) armonizar los distintos sistemas nacionales de preferencias comerciales; incrementar el radio de estas preferencias de modo de alcanzar un mayor número de productos manufacturados $y$ agricolas procesados; y eliminar, o al menos aliviar, los actuales límites en el monto permitido de comercio;

(b) modificar el esquema de preferencias comerciales con el objeto de alentar la integración regional de los paises en desarrollo;

(c) reducir los efectos comerciales que acarrean los aumentos de aranceles para matcrias primas procesadas;

(d) definir reglas aceptables referentes a subsidios de exportación y tratamicnto preferencial para países en desarrollo cuando 
éstos impongan aranceles de compensación ("countervailing duties");

(c) reducir y eliminar gradualmente todas aquellas barreras arancelarias, como cuotas de productos y acuerdos de restricción voluntaria de exportación, cuyo efecto es inhibir a largo plazo la expansión y diversificación de las exportaciones de los paises en desarrollo;

(f) desarrollar medidas que mitiguen las consccuencias adversas de los esquemas de comercio que están en vigor entre la Comunidad Europea y ciertos países en desarrollo, o eliminar tales esquemas comcrcialcs siempre que sea posible, y

(g) establecer sanciones para cierres de mercados al margen de la ley, que no estén de acuerdo con los principios de la "General Agreement on Tariffs and Trade" (GATT), y fomentar la armonización de politicas nacionales de ajuste;

18) El Congreso de Estados Unidos deberia revocar Ia cláusula discriminatoria referente al sistcma general de preferencias arancelarias, de la "Trade Act" de 1974", con el objeto de excluir a aquellos miembros de los Países Exportadores de Petróleo (OPEP) que no participaron en el embargo contra Estados Unidos ${ }^{30}$;

19) El gobierno de Estados Unidos deberla presentar rápidamente un plan propio que contemple adecuadamente las fluctuaciones de precios de las mercaderias y la disminución en las ganancias por conccpto de exportaciones. La nueva administración debería consultar en estas materias con los paises iberoamericanos que se encuentran en los mercados en la privilegiada situación de ser, al mismo tiempo, compradores y vendedores;

20) El Presidente deberia nombrar un coordinador a alto nivel que acclere dentro de Estados Unidos los preparativos y movilice apoyo del sector privado respecto a la Conferencia de las Naciones Unidas sobre Ciencia y Tecnologin que se celebrará en 1979;

21) Conjuntamente con organizaciones regionales iberoamericanas, Estados Unidos debería ayudar a establecer en América Latina instituciones multinacionales de ciencia c investigación dedicadas a desarrollar tecnologías, y promover asistencia técnica y cooperación científica horizontal entre los paises de la región;

22) El Presidente Carter deberia reemplazar la política enunciada en enero de 1972 sobre expropiación, por una declaración que defina claramente la actitud de Estados Unidos sobre la protección de los legitimos intereses económicos de este país en el extranjero; asimismo, se deberían identificar instrumentos alternativos que resuelyan las disputas por nacionalización, sin que sea necesario recurrir a sanciones económicas;

23) Esta Comisión apoya los recientes esfucrzos hechos por Estados Unidos en las Naciones Unidas para negociar un nucvo tratado en que se requiera una divulgación más extensa y armonizada de la información proporcionada por empresas transnacionales y se establezcan sanciones apropiadas relativas a sobornos y extorsiones cometidas por sociedades privadas o representantes gubernamentales. El nuevo gobiemo deberia pre-

as Que excluyó a los paises exportađores de petróleo de preferencias comerciales, entre ellos a iEcuador y Venezuela, a pesar que estas naciones aumentaron sus exportaciones de este combustible a Estados Unidos durante el periodo del embargo.

3a Esta medida está destinada a fayorecer a Ecuador y Ven'ezuela. 
sionar vigorosamente para obtener la aprobación internacional a este nuevo tratado;

24) Estados Unidos debcría adoptar una posición de liderazgo en la fortificación del Comitć de Desarrollo del Fondo Monetario Internacional y Banco Mundial, con el objeto que este Comité sirva como un grupo de trabajo que movilice recursos para destinarlos a prioridades convenidas de desarrollo, y cxamine y cvalúc la implementación ocurrida en las transferencias de jecursos;

25) Esta Comisión comparte otros estudios anteriores (que incliyen cl Panel on International Information, Erlucation and Cultural Relations" o "Stanton Paujel", y la "Commission on the Organization of the Government for the Conduct of Foreign Policy" o "Murphy Commission"), los cuales recomiendan que en la dliplomacia de Estados Unidos se separen claramente las relaciones culturales de las funciones propiamente po. líticas. La labor de los agregados culturales en las embajudas y personal dedicado a las relaciones culturales internacionales on Washington, debería recibir un aumento de recursos financieros y radio de acción;

26) Se necesita aumentar considerablemente los recursos que financian la "Fulbright-Hays Acl" y el Tílulo yi de la "National Defense Education Act". De esta manera se podria proveer fondos para cubrir importantes nuevos programas destinados a aumentar el conocimiento, comprensión y conciencia sobre América Latina entre los norteamericanos;

27) Los diez millones de dólares que ahora han sido autorizados para financiar investigaciones avanzadas sobre asuntos exteriores bajo la "International Education Act" de 1966, deberian ser distribuidos por el Congreso;

28) Deberfa crearse un nuevo Conscjo sobre Relaciones Culturales entre Estados Unidos Y América Latina para examinar el estado general de estos vínculos $y$ desarrollar programas especificos en materia de artes y humanidades. Con este propósito, fondos iniciales deberían ser provistos por la "National Endowment for the Arts", "National Endowment for the Humanities" y, si es posible, por instituciones similares latinoamericanas.

Aparte del Informe Linowitz que, como se ha dicho, cumple una función extraoficial, la única declaración de principios global hacia América Latina emitida por Carter se encuentra en su discurso ante el Consejo de la OEA (I4 de abril), citado más arriba. Este mensaje sólo refleja las ideas del Informe Linowuitz. Entre las pocas ideas nuevas que contiene se destacan éstas: es necesario adaptar las instituciones interamericanas a las nuevas realidades políticas y' económicas; Ias relaciones de Estados Uniclos con América Latina se han tornado más equilibradas a medida que los paises iberoamericanos han comenzado a jugar un papel más independiente e importante en la política mundial; el hecho que ahora Estados Unidos busca disenar politicas que tengan en cuenta las particularidades de cada país latinoamericano, no significa que se pretende dividirlos o separarlos del resto del mundo; Estados Unidos desea entrenar técnicos latinoamericanos para que éstos hagan mejor uso de la información recogida por los satélites norteamericanos, como una primera muestra de su intención de prestar una ayuda efectiva de carácter científico $y$ 
técnico; se requiere establecer una mayor cooperación interamericana respecto a problemas que trascienden las fronteras, como tráfico de drogas y terrorismo internacional; Estados Unidos pretende fortalecer la OEA ${ }^{40}$; Estados Unidos apoya los esfuerzos latinoamericanos para lograr una integración regional o subregional.

\section{$\mathbf{V}$}

Esta sección se dedica a examinar quiénes son los hombres claves encargados de la aplicación de la política de Carter hacia Iberoamérica.

El nombramiento de algunas de csas personalidades ha tenido cierto revuelo. Desde luego, la clección de ciertos embajadores que han de servir en América Latina ha creado disgustos en ciertos círculos del Partido Demócrata. Harry Shlaudeman fue designado en Perú, a pesar que en 1976 se le acusó de no haber informado al Congreso acerca de su conocimiento de las actividades subversivas en Chile, lugar en el cual trabajara antes del golpe militar. En ese entonces, Shlaudeman logró su nombramiento como Subsecretario cle Estado para asuntos interamericanos no obstante estas críticas. En E1 Salvador, Sally Shelton (primera embajadora en América Latina) representa a Estados Unidos. Shelton se ha destacado en el pasado en la defensa de los derechos humanos. El Salvador constituye una de las mayores pruebas a la política ce Carter sobre derechos humanos considerando las serias acusaciones hechas respecto a la violación de éstos, incluyendo la desaparición de un ciudadano norteamericano ${ }^{41}$, que se cree ha sido asesinado por la policía. En el cono sur, dos miembros de minorías raciales han sido designados embajadores: en Argentina, Raúl Castro, chicano ${ }^{42}$, y, en Chile, se propuso a Davicl Carlisle, un ingeniero civil de raza negra que estudió en la acade-

40 Sin embargo, el Canciller Vance ha propuesto rebajar el aporte norteamericano al presupuesto de la oEA de 66 por cięnto a 49 por ciento. También Esiatos Unidos ha manifestado sa deseo que Ecuador y Venczuela aumenten su participación en este financiamiento.

Algunos observadores han creido que esta actitud norteamericana obedece a la iatención de disminuir las criticas contra Estados Unidos por su dominación dentro de esa organización.

"1 Ronalel J. Richardson.

${ }^{42} \mathrm{E}_{1}$ el extranjero a veces se piensa que chicano es una expresión peyorativa. Lejos de ello. En efecto, algunos latinoamericanos o desccndientes de éstos que viven en Estados Unidos descan que chicano comprenda no sólo a los descendientes de mexicanos que son ciudadanos norteamericanos, sino que a todos los "Latins" con residencia en este pais. Tstos descendientes de mexicanos se dan a si mismos el nombre de chicanos; no st trata de una expresión impuesta sobre ellos. Este autor se siente honrado de ser considerado un "chicano honorario".. 
mia militar de West Point, circunstancia que hizo pensar, equivocadamente, que facilitaria el contacto con la junta de gobierno. Más tarde, la proposición de Carlisle fue reemplazada por la de George Landau. En México fue designado Patrick Lucey, ex gobernador de Wisconsin, quien hace poco recibió una tajante negativa del gobierno de López Portillo a su ofrecimiento de ayudar a conseguir créditos externos si éstos se dedicaban a desarrollar los recursos petroleros mexicanos.

El cargo de embajador ante la OEA ha recaido en el ex senador Gale McGee, quien ha sido un ardoroso defensor de la renegociación del tratado del Canal de Panamá. Este nombramiento confirma el interés de Carter por firmar un nuevo convenio con Panamá. Se dice, sin embargo, que McGee es un burócrata sin imaginación ni iniciativa.

Una de las designaciones más difíciles fue la del diplomático de carrera, de raza negra, Terence Todman en el puesto de Subsecretario de Estado para Asuntos Interamericanos. Grupos y personalidades interesadas en América Latina trataron de evitar este nombramiento, porque se considera que Todman no romperá totalmente con la política anterior hacia Iberoamérica. Aquellos han alegado que Todman tiene sólo dos años de experiencia en América Latina 43 y no ha demostrado ninguna preocupación por la situación de los derechos humanos en la región ${ }^{44}$; además, se ha dicho que esta designación sólo obedece a motivos de política interna. Se rumorea que Todman considera "comunista" cualquier intento reformista y que está relacionado con el "American Institute for Free Development" 45, que desde la década de 1950 ha actuado conjuntamente con la "Central: Intelligence Agency" (CIA) en contra de grupos laborales comunistas en América Latina.

\section{VI}

En este capítulo se analiza la situación práctica de las relaciones interamericanas en 1977.

En su primera semana como gobernante (enero de 1969), Nixon

ta Ha sido cmbajador en Costa Rica po: dos años. En este cargo mostró pasividad ante dos de los mayores problemas de este pais: eliminación de las cuotas que restringen las exportaciones de carne y azuicar, y extradlición de Robert Vesco.

14 Lawrence R. Birns, director del "Council on Hemispheric Affairs" ha alegado esta falta de interés por los derechos humanos en América Latina. Véase: The New York Times. 13 de enexo de 1977, p. 9.

45 La sccción internacional de la mayor organización laboral norteamericana, AFL-CIO ("American Federation of Labor-Congress of Industrial Organizations"). 
tuvo que afrontar una grave crisis en América Latina. En ese mes, Perú nacionalizó la "International Petroleum Company", dándose lugar entonces al fenómeno conocido como "peruanismo". En cambio, Carter no ha tenido que sufrir tensiones de esta clase en un período semejante, a pesar de ciertos choques iniciales en materia de derechos humanos.

Además de los derechos humanos, los problemas más urgentes que Estados Unidos debe enfrentar en sus relaciones interamericanas son: armamentismo, no proliferación nuclear, barreras arancelarias a productos manufacturados Iatinoamericanos, vigencia de un nuevo tratado sobre el Canal de Panamá, restablecimiento de relaciones diplomáticas con Cuba, independencia de Puerto Rico, inmigrantes ilegales latinoamericanos (especialmente mexicanos), asilo político a disidentes latinoamericanos, esfuerzos por controlar el capital extranjero y las empresas transnacionales, rivalidad creciente entre Argentina, Brasil y México por conquistar el liclerazgo de América Latina, problemas fronterizos entre países latinoamericanos, y el DESARROLLO ECONOMICO de este continente, materia que no en vano se debe escribir con maýúsculas.

Con el objeto de demostrar su simpatía hacia América Latina, Carter mandó en el mes de mayo a su esposa en una gira de doce días, en la cual recorrió Brasil, Colombia, Costa Rica, Ecuador, Jamaica, Perú y Venezuela.

El envio de estas misiones forma parte de la politica tradicional de Estados Unidos hacia Iberoamérica, práctica que se remonta a 1817, fecha en la cual ese pais mandó a Hispanoamérica una delegación de doce personas, presidicla por Theodorick Bland, con el encargo de nombrar un cónsul general de entre sus miembros ante los gobiernos que se consideraran estables. Desde entonces, Estados Unidos ha enviado misiones al sur cada vez que ha querido mostrar su buena voluntad o cuando las relaciones se han tornado frias, peligrosas o inestables. Entre estas embajadas se cuentan las de Adlai Stevenson, David Rockefeller, William Rogers, Henry Kissinger, y una de triste memoria de Richard Nixon ${ }^{46}$.

Esta clase de delegaciones, incluyendo la de Rosalynn Carter, ha tenido escasa importancia práctica y ningún impacto en la opinión pública latinoamericana (salvo cuando a ésta se le permite demostrar contra los "yankis") . A menudo estas misiones recuerdan la historia de los grandes imperios que mandaban emisarios a sus colonias, las cuales se debian mostrar satisfechas con la enorme gracia que se les concedia. Muchas veces las cancillerías latinoamericanas han pedido que altos representantes de Estados Unidos vay'an a América Latina;

to Un recuento autobiográfico de esta gira se puede leer en: Richara Nixon: Seis Crisis. Barcelona, Ediciones G. P., 1967, pp. 209-265 
pero estos mensajes son mal interpretados en Washington: alli se cree que se les está picliendo un favor, cuando lo que se solicita es una relación interamericana más igualitaria. En efecto, los presidentes y ministros latinoamericanos deben ir a la Casa Blanca, pero los moradores de esta mansión se sienten exceptuados de atravesar el Río Grande.

No obstante el carácter aséptico e inodoro de la girn de la señora Carter ${ }^{17}$, ésta demostró las preferencias del presidente norteamericano por los gobiernos democrálicos como se puede ver en los países visitados y el ardoroso apyyo daclo por esta misión a los planes electorales de Ecuador (incluso Rosalynn Carter se entrevistó con el presidente del tribunal electoral supremo de ese pais). La embajadora norteamericana visitó sólo tres dictadores: los de Brasil, Ecuador y Perú. Con respecto a Ecuador ya se ha hecho notar la intención que se perseguia. Brasil ha tenido, especialmente desde los días de Kissinger, un status especial dentro de la política exterior de Istados Unidos debido a su importancia económica y militar. Quizás se prefirió pasar por Perú, en lugar de otros asientos de dictadores, para demostrar que ahora Estados Uniclos no siente pánico por los gobiernos izquierdistas (a unque es discutible si se puede dar este apellido al presente régimen peruano); asi se podría explicar también la actitud de gran cordialidad que la señora Carter mostró hacia el jefe de estado jamaicano.

Hasta el momento, el paso más importante dado por Carter en las relaciones interamericanas ha sido la firma de un nuevo tratado con Panamá, que fue precedida por catorce años cle inútiles discusiones. Sol Linowitz fuc el principal representante de Carter en la renegociación de este convenio sobre un canal que ya no es económica o militarmente importante para Estados Unidos (sólo el 10 por ciento de su comercio exterior transita por allí y los grandes portaaviones $y^{t}$ buques no pueden hacerlo).

El nuevo tratado establece un aumento gradual de la participación de Panamá en la defensa y operación del canal hasta el año 2000, fecha en la cual estas funciones le corresponclerán totalmente. Conforme al tratado de neutralidad anexo al convenio principal, ambos países acuerdan que el Canal será neutral y que se garantizará el derecho a prioridad y tránsito de los buques de guerra nortcamcricanos. Estados Unidos se reserva el clerecho a intervenir militarmente en cualquier momento con el objeto de hacer respetar la neutralidad del Canal.

Buenas razones ha tenido Carter para firmar este tratado al comienzo de su mandato. Desde luego, era necesario mostrar con he-

47 Cuando se ha querido verdaderamente halblar de negocios, se ha mandado, por ejemplo, al Canciller Vance a Brasil. 
chos que ahora Estados Unidos desea basar las relaciones interamericanas en el respeto a la soberanía de cada país latinoamericano, por muy pequeño que éste sea. Por otra parte, en pocas materias se encuentra el Tercer Mundo tan unido como frente al problema del Canal de Panamá, y un nuevo diálogo con los países en desarrollo requería afirmar con hechos un nuevo espíritu. Además, incluso naciones industrializadas como Francia han dado su apoyo a Panamá y este asunto se ha transformado en motivo de acusación universal contra Estados Unidos. Asimismo, el problema del Canal de Panamá es una materia internamente delicada en una sociedad en la que muchos creen que Estados Unidos tiene tanto derecho al Canal como al Río Mississippi. Asi, este tratado no se podría haber firmado en una fecha inmediatamente anterior a una elección presidencial o parlamentaria.

En 1977, el gobierno de Carter ha volcado todas sus fuerzas en conseguir que el Congreso ratifique este convenio y adiopte su programa sobre energía. Es posible que la votación en el Congreso se aplace hasta 1979. Primitivamente se ha creído que ésta podria tener lugar en marzo o abril de 1978, pero en noviembre son las elecciones parlamentarias y además la obligación que Estados Unidos contrae de pagar cerca de dos millones de dólares a Panamá en los próximos veinte años para la mantención del canal, ha hecho pensar que Ia Cámara de Diputados también debería intervenir en la discusión de la ratificación, con lo cual el clebate se alargaria más de lo esperado. Se prevé que la votación será estrecha, aunque los esfuerzos de Carter y la declaración del Presidente Torrijos respecto a la defensa norteamericana de la zona a partir del año 2000 y el paso expedito de los buques de Estados Unidos, podrian cambiar el panorama. Por otra parte, Torrijos ha dado algunos pasos hacia la democratización del país con el objeto de evitar que el Senado norteamericano vincule el problema del Canal con el de los derechos humanos.

Carter ha ciebiclo afrontar una clura oposición al nuevo tratado, la cual ha tenido entre sus lideres más renombrados a Ronald Reagan. Por ejemplo, en noviembre, la "American Conservative Union" patrocinó un programa de televisión de treinta minutos en contra del tratado en veintinueve estaciones de Floricla, Louisiana y Texas, a un costo de 65 mil dólares. Este programa, titulado "There is No Panama Canal: There is an American Canal in Panama", en el cual aparecen varios senadores derechistas, será mostrado en otras cuarenta y cinco estaciones del sur y sudoeste de Estados Unidos y, si se consiguen más fondos, en dieciocho otros estados de la federación norteamericana. Los opositores al tratado, que entre otras cosas alegan que no se debe incurrir en un "nuevo Vietnam", sólo necesitan treinta y cuatro votos para impedir la ratificación. Si ésta no se lo. 
gra, Estados Unidos se verá en una difícil situación internacional (por ejemplo, enfriamiento de las relaciones interamericanas y rebrotes de nacionalismo en Iberoamérica) y deberá afrontar serios peligros de ataques guerrilleros en Ia zona del canal.

EI 7 de septiembre, con ocasión de la firma del nuevo tratado, se reunieron en Estados Unidos, a invitación de la oEA, los gobernantes de la mayoría de los países latinoamericanos, dándose tugar entonces a un raro espectáculo, que la expresión inglesa "extravaganza" describe mejor, en el cual tomaron parte dictaclores de todos los pelajes. Carter ha sido durtmente criticado por haberse entrevistado con algunos de éstos. Pero esta circunstanciá permitió al presidente norteamericano tener la oportunidad, al poco tiempo de asumir el poder, de intercambiar opiniones con la casi totalidad de los jefes de estado de las Américas, sin perjudicarse demasiado considerando las razones que trajeron a éstos a Listados Unidos. A su vez, esta ocasión fue aprovechada por los representantes latinoamericanos para discutir importantes materias con Carter. Argentina buscó establecer una política conjunta con Estados Unidos, Colombia y Venezuela sobre derechos humanos; Perú clesé el apoyo norteamericano en sus problemas con el Fondo Monetario Internacional; Ecuador y Venezuela persiguieron el levantamiento de la discriminación arancelaria que los afecta por ser miembros de OPEP; Colombia manifestó su preocupación por el tráfico internacional de drogas y la situación en el mercado mundial del café. Por su parte, Chile usó la oportunidad para tratar de mejorar su imagen internacional; en tanto que los miembros del Pacto Andino buscaron una salida a los problemas de este sistema de integración económica. Discusiones sobre problemas fronterizos fueron celebradas entre los presidentes de El Salvador y Honduras; Bolivia, Chile y Perú; y Ecuador y Perú. Además, Guatemala solicitó el apoyo norteamericano para tratar la cuestión de Bélice.

Las conversaciones para reanudar las relaciones con Cuba se han estancado, a pesar que en enero y febrero el Canciller Vance se mostrara optimista con respecto a esta posibilidad. Han contribuido a la presente situación de estas negociaciones los recientes informes que indican que el número de cubanos en Africa ha aumentado ${ }^{48}$. Además, la mala cosecha en Cuba y la disminución del precio mundial del azúcar han reducido las presiones de los hombres de negocio de Estados Unidos sobre su gobierno, porque ahora éstos creen que la isla no ofrece las mismas buenas perspectivas de antes como mercado norteamericano.

4 Algunos observadores han indicado que el número de cubanos en Africa, excepto en Angola, no ha aumentado. Lo que habría ocurrido es que ahora se Ies ha querido "descubrir". 
A pesar de la lenta marcha de estas discusiones actualmente las partes poseen un acuerclo sobre delimitación maritima y un convenio relativo a la pesca ${ }^{49}$; aclemás, Cuba ha dado su consentimiento tácito a la continuación del tratado referente a la piratería aérea ${ }^{50}$. Por otra parte, funcionan "secciones de interés" norteamericana en la embajada suiza en La Habana y cubana en la embajada checoslovaca en Washington. Estas oficinas han permitido otorgar visas, reunir familias y fomentar el intercambio académico, cientifico y cultural.

En el futuro, los puntos más difíciles de negociar entre Estados Unidos y Cuba serán: control de las actividades cle los exiliados cubanos; compensación a la propiedad norteamericana expropiada en 1959; levantamiento del boicot comercial; existencia de la base militar de Guantánamo; apoyo de Cuba a Angola y a la independen. cia de Puerto Rico.

Este último punto nos trae a una novedad en las relaciones inter. americanas. Ahora, Estados Unidos no considera el destino de Puerto Rico como una materia de su exclusiva competencia interna y ha apoyado el principio de autodeterminación del pueblo de la "isla del encanto" 51. Descle luego, en septiembre Estados Unidos por primera vez participó en el Comité de Descolonización de Ias Naciones Unidas en la discusión del proyecto cubano relativo a la indepen. dencia de Puerto Rico. Esta nueva actitud, y las tácticas adoptadas por la potencia norteamericana, permitieron por tercera vez aplazar (luego de una votación de once a favor y siete en contra) para el póximo año la discusión de la propuesta cubana.

La política de Carter sobre derechos humanos en Iberoamérica ha despertado grandes polémicas. Algunos observadores se han mostrado satisfechos con los resultados de las presiones de Estados Unidos 52: los gobiernos militares habrian liberado prisioneros políticos; y Bolivia, Chile, Ecuador, Perú y Uruguay han anunciado la vuelta a regímenes democráticos (lo cual basta para muchos, aunque los plazos sean largos, las reglas del juego desconocidas y falta quien garantice que el viento no se llevará las promesas). Otros, en cambio, creen que Carter es un bufón en su defensa de los derechos huma-

4t Ambos acuerdos fueron negociados a aito nivel en el Roosevelt Hotel de New York. El Secretario de Estado, Terence Todman, representó a Estados Unidos, y el Subsecretario de Relaciones Exteriores, Pelegrin Torras, a Cuba.

so El convenio sobre pirateria aérea debía terminar el 15 de abril, seis meses después que Cuba notificara su intencion de ponerle fin luego del atentado aéreo cometilo en Barbados.

t1 "Isla del encanto" o "Borínquen" son los nombres que generalmente los puertorriqueños dan a su pais.

w Véase, por ejemplo, el artículo de Anthony Lewis en: The Now York Times. 28 de febrero de 1977 , p. 27. 
nos y apuntan especialmente a la continua concesión de ayuda económica a las dictaduras ${ }^{53}$.

La política de Carter sobre derechos humanos ha recibidlo su batltismo de fuego en América Latina debido al crecido número de gobiernos militares en este continente ${ }^{5.4}$. Este hecho, unido a la acusación que Estados Unidos ha colaborado en muchos casos a su instalación y al impacto que han tenido las noticias acerca de violaciones a los derechos humanos en esa región, han impulsado a la opinión pública norteamericana a presionar sobre Carter con el objeto de conseguir resultados concretos en Iberoamérica.

La tarea más dura de Carter en su defensa de los derechos humanos, tanto en América Latina como en otros continentes, ha sido la elaboración de criterios que permitan discriminar entre distintos casos y países. La falta de coherencia en las pautas diseñadas han restado fuerzas a la política norteamericana en esta materia. Entre los muchos aspectos que requerirían mayor atención se encuentran éstos: qué importancia deben recibir aquellos derechos que tienen mayor relevancia económica que política (v.gr., el derecho al empleo); en qué medida se debería armonizar la protección de los derechos humanos con otros objetivos internacionales como la no pro. liferación nuclear; ¿sería necesario efectuar una clara distinción entre naciones aliadas y enemigas, o entre gobiernos a los cuales Estados Unidos les ayudó a establecerse en el poder y paises que, aunque rivales, mantienen estrechos vínculos con Estados Unidos?; ¿sería más aconsejable que Estados Unidos actuara conjuntamente con otras naciones (por ejemplo, a través de un tratamiento multilateral de concesiones comerciales) o por medio de organizaciones internacionales ${ }^{65}$ ?; ¿qué clase de premios y castigos se deberian otorgar?; ¿cómo solucionar el problema que se crea cuando las acciones de Estados Unidos contra un gobierno perjudican directamente al pueblo en cuyo favor se aboga por los derechos humanos?; ¿cuán pronto se

Wéase especialmente: Stu Cohen: of Human Rights and Global Economics; Carter's Latino American Policy Runs into Questions in Chile. En: The Boston Phoenix. 26 de octubre de 1977. P. 16.

* Por ejemplo, en Sudamérica existen actualmente sólo cinco democracias: Colombia, Guyana, Guyana Francesa, Surinam y Venezuela. Esta situación contrasta, por ejemplo, con la mayor libertad que existia en 1961.

Los países con gobiernos militares y la fecha de su instalación son: Argentina (1976), Bolivia (1964 o 1966, según cuán democrática se considere la elección celebrada en ese último año), Brasil (1964), Chile (1973), Ectadlor (1972), Paraguay (1954), Perú (1968) y Uruguay (1973).

* Con respecto a las organizaciones internacionales, el diputado demócrata por Iowa, Iom Harkin, expresó cl 23 de marzo de 1977 ante la Cámara de Diputados que las polfticas fiscales exigidas por instituciones que conceden préstamos: a menudo son causa de la repres:ón ejercida en los paises receptores de la ayuda. 
esperan los resultados a las presiones ejercidas?; ¿cómo y cuándo se deberían efectuar evaluaciones sobre las acciones tomadas?

Conforme a las recomendaciones del Informe Linowitz, Carter firmó, el 19 de junio, la Convención Americana sobre Derechos Humanos (la cual aún debe ser ratificada por el Congreso). Este acuerdo fue firmado originalmente en Costa Rica en 1969 por dięz gobiernos, pero hasta el momento sólo Colombia y Costa Rica lo han ratificado. Estados Unidos no había firmado este documento antes debido a las cláusulas económicas y sociales que contiene.

En gran parte debido a la iniciativa de Estados Unidos, la reunión de la Asamblea General de la o£s, celebrada en Grenada en junio, se dedicó a discutir el problema de los derechos humanos. Especialmente los cancilleres de Argentina y Chile afirmaron que el aspecto más importante en esta materia es el terrorismo; a lo cual Estados Unidos respondió que no se puede combatir el terrorismo sino que con justicia social, económica y jurídica,

En esta reunión de la OEA se aprobaron dos resoluciones. Una de éstas ${ }^{50}$ señala la necesidad de aumentar los recursos de la Comisión de Derechos Humanos de la OEA, cooperar con el trabajo de ésta, permitir la visita de esta comisión a los países miembros. También prohíbe a los estados americanos suspender o interferir con los derechos individuales fundamentales, tales como ausencia de torturas, ejecución sumaria y detención prolongada. La otra resolución ${ }^{57}$ solicita a la Comisión de Derechos Humanos de la ona que busque nuevas formas de cooperación hemisférica para combatir el terrorismo. Originalmente los gobiernos de Argentina, Chile, Paraguay y Uruguay habian cleseado fundir estas dos resoluciones en una sola.

En su discurso ante la oEA, en abril, Carter afirmó expresamente que Estados Unidos favorecerá a los países que respetan los derechos humanos y promueven valores democráticos. Su gobierno desea demostrar esta actitud a través de medidas econónicas. Sin embargo, no se comprende cómo Estados Unidos no ha levantado aún su discriminación arancelaria contra Venezuela, a pesar de ser ésta una de las pocas naciones democráticas en Sudamérica. Con respecto a Ecuador, otro miembro de la opEP al cual le afecta la discriminación arancelaria, se podría retardar este levantamiento hasta el día de las elecciones fijado en 1978, especialmente ahora que se ha rumoreado que ciertos sectores de ese pais no están muy dispuestos a pasar el poder a manos democráticas.

El problema de la violación de los derechos humanos se relaciona

ris Aprobada por catorce votos (el resto de los miembros de la oes se abstuvo). Esta resolución lue presentada por Estados Unidos y fue patrocinada támbién por Costa Rica, República Dominicana y Venezuela,

${ }^{67}$ Aprobada por unanimidad $y$ apoyada ardientemente por el representante norteamericano. 
con la concesión de ayuda económica y militar, y venta de armamento. En la discusión de estas materias, el Congreso norteamericano ya ha demostrado su intención de participar más activamente en la formulación de la política sobre derechos humanos.

Actualmente no se han otorgado nuevas autorizaciones para el entrenamiento y venta de implementos a las policias iberoamericanas (lo cual se ha hecho en el pasado bajo el "Public Safety Program", patrocinado por el "Federal Bureau of Investigation", FBI) y sólo continúan los programas que habian sido aprobados en los gobiernos anteriores. La misma situación se registra con la donación de armamento. También se han disminuido los programas de entrenamiento militar. Lo que sí continúa es la venta de armamento militar a través de los "foreign military sales", que constituyen una forma de transacción comercial que recibe un fuerte subsidio del gobiemo norteamericano.

Las divisiones que existen en Estados Unidos entre los poderes públicos y los departamentos encargaclos de la aplicación de la política exterior, han quedado claramente demostradas al discutirse las violaciones a los derechos humanos en Argentina, Brasil, Chile y Uruguay. Incluso en el caso cle Chile, acerca del cual existe mayor consenso, numerosas críticas se han hecho por funcionarios públicos a la forma como el Subsecretario Todman ha manejado las relaciones con este país ${ }^{58}$. Jin efecto, se ha alegado que a pesar de la terminación puesta por el Congreso en 1976 a la ayuda militar, Chile ha sido capaz de evadir las consecuencias de ésta usando a Brasil de trampolín, además de recibir 357 millones de dólares en ayuda económica en ese mismo año.

Ẽn junio, el Departamento de Estado recomendó (luego de agitadas controversias internas) que se postergara el otorgamiento de dos préstamos agrícolas a Chile, los cuales estaban siendo considerados por la "Agency for International Development" (AID). Al conocer esta determinación del Departamento de Estado, el gobierno de Pinochet comunicó su intención de no recibir dinero de la Ard: al día siguiente aquel ministerio canceló los fondos de esos empréstitos.

El 23 de febrero, el Canciller Vance anunció la reducción de la ayuda económica y militar a Argentina y Uruguay debido a las violaciones a los derechos humanos cometidas por estos países ${ }^{59}$. La

\footnotetext{
ss Véase: Stu Cohen: Of Human Rights and Global Economics, Carter's Lam tin American Policy Runs into Questions in Chile. Op. cit., pp. 36-37.

"9 Los créditos militares ("foreign military sales") de 3 millones de dólares fueron totalmente terminados a Uruguay, y la asistencia económica fue reducida de $220 \mathrm{mil}$ dólares a 25 mil dólares.

E1 I5 de junio los senadores Church y Kennedy introdujeron una enmienda al "International Security Assistance and Arms Export Control Act" de 1976, en virtud de la cual se terminaria con toda la ay'uda, venta $y^{\prime}$ créditos milita-
} 
reacción de estos países fue rechazar los créditos militares ${ }^{00}$. Lo propio hizo Brasil con respecto a 50 millones de dólares al conocerse en Brasilia un informe del Departamento de Estado sobre la situación de los derechos humanos en ese país. Aclemás, Brasil ha cancelado el acuerdo de 1952 sobre defensa. mutua celebrado con Estaclos Uniclos. En Brasilia se espera que la preocupación por los derechos humanos no afecte las relaciones comerciales, especialmente ahora que Brasil busca la renegociación de su cleuda externa cle 30 mil millones de dólares.

Algunos observadores han alegado que las mediclas económicas y militares adoptadas contra la violación a los derechos humanos, disminuye la influencia cle Estados Unidos en los países afectados. Sin embargo, es necesario apuntar que esas medidas no han tenido las repercusiones económicas que se pudiera creer. Desde luego, los grandes bancos privados norteamericanos (como Chase Manhattan, Citicorp y Bank of America) están aumentando vertiginosamente sus préstamos a países iberoamericanos. Además, existen numerosos resquicios legales que permiten evitar la disminución de los recursos militares; por ejemplo, en 1975 el Departamento de Justicia (a través del 'Drug Enforcement Administration') otorgó a Argentina 81 mil dólares para combatir el tráfico de drogas y una cantidad no especificacla, a ser discribuida entre 1975 y 1977 , clestinaclas a adiestramiento policial, sumas que se cree que en la práctica serán aplicaclas a programas de "seguriclad interna" ${ }^{01}$. Por otra parte, existe la intención (como quedó demostrado en febrero con la intervención de C. Fred Bergsten, Subsecretario del Tesoro, ante el Congreso) de canalizar gran parte de la ayuda económica a través de instituciones multilaterales como Banco Interamericano de Desarrollo, Fondo Monetario Internacional y Banco Mundial. De esta manera, Carter podría condenar en los discursos y, al mismo tiempo, prestair indirectamente apoyo económico. La ayucla otorgada por estas organizaciones Ilevaría un sello internacional; además, las concesiones hechas por éstas no requieren aprobación del Congreso ${ }^{62}$. Préstamos

res a Argentina. Este proyecto produjo apasionados debates en el Congreso y, finalmente, se llegó al compromiso de aplazar el otorgamiento de esta ayuda hasta septiembre de $197 \mathrm{~S}$. Por otra parte, el 22 de junio la Cámara de Diputados acordó (por 223 votos contra 180) detener el programa de entrenamiento militar a Argentina (el cual tiene un financiamiento de 700 mil dólares y que ha entrenado 4.000 militares en los tiltimos 27 años, tanto en Estados Unidos como en Panamá).

a) En el caso de Argentina se trata de 15 millones de dólares.

"Latin American Political Report. Lonton. Vol. Xr, No 15. 22 de abril de 1977. P. 69.

ca pesar que la ayuda otorgada a través de estas instituciones llevaría un 
hechos por instituciones multilaterales han ayudado en el último tiempo a la subsistencia de regímenes de facto ${ }^{63}$. Un reciente informe ${ }^{64}$ ha señalado que el 69 por ciento de la ayuda extranjera otorgacla por Estados Unidos a los países en desarrollo no es revisada por el Congreso.

En febrero el Canciller Vance señaló que en la concesión de ayuda económica se considerará el problema de la proliferación nuclear. Esta declaración se emitió pensando en Brasil, país con el cual Estados Unidos ha mantenido tensas conversaciones relativas al convenio celebrado en 1975 entre Bonn y Brasilia, a través del cual se provee el establecimiento de plantas de reprocesamiento de combustible y enriquecimiento de uranio en ese país latinoamericano ${ }^{05}$, permitiéndose así la obtención de plutonio y, por ende, la posibilidad de poseer la bomba atómica.

Brasil ha debido afrontar oposición interna a su programa nuclear ${ }^{86}$, además de reacción internacional. Así, el Presidente cle Venezuela, en su mensaje anual al Congreso, condenó el convenio entre Alemania y Brasil (aunque sin nombrar a las partes) y afirmó su

sello internacional, la mayoría de votos que Estados Unidos tiene en muchas de éstas le permitiría bloquear créditos.

En abril fue rechazado el proyecto presentado en el Congreso por los representantes Farkin y Badillo, conforme al cual Estados Unidos vetaría en las instituciones internacionales préstamos solicitados por dictaduras, salvo que éstos estuvieran destinados a favorecer directamente a los sectores más necesitados de la población. En cambio, se aprobó un proyecto del Pres:dente Carter que no contempla el derecho a veto y que excluye la participación del Congreso en esta materia.

Desde 1976, el Banco Interamericano de Desarrollo hatorgado a Argentina dos préstamos por 150 millones de dólares, el Banco Mundial uno por 115 millones de dólares (septiembre de 1976) y el Fonclo Monetario Internacional ha aumentado el derecho de Argentina a hacer uso de los "Special Drawino - Rights" de 64 millon'es a 700 millones de dólares entre 1975 y 1977.

as Center for International Policy. Enero de 1977.

* A fines de febrero, las discusiones se enfriaron completamente debido a la negativa de Brasil de dar por terminado este convenio a cambio de la obligación de Estados Unidos de abastecerle en el futuro de combustible nuclear. Además, en ese mes, tras la visita del Vicepresidente Mondale a Europa Occidental y Japón, quedó en claro que Estados Unidos estaba más interesado en decidir la materia sin el concurso de Brasil. Una muestra de los efectos de las presiones de Estados Unidos en Europa es la declaración del Canciller holandés, emitida ese mismo mes, en la cual señaló que como condición previa a la entrega de los primeros dos reactores nucleares a Brasil (conforme al acuerdo firmado con Alemania en 1975), ese país debería aceptar que los clesperdicios producidos por las plantas enriquecedoras de uranio sean devueltos a URENCO, un consorcio alemán-británico-holandés encargado de la construcción de las plantas.

* Véase: Latin American Political Report. London. Vol. XI, N\& 14. 8 de abril de 1977, p. 1I0, 
cleseo que la energía atómica se encuentre bajo control de una autoridad supranacional. Por otra parte, el Ganciller holandés manifestó ante el Congreso que los Países Bajos sólo permitirian la venta de uranio enriquecido a Brasil si este país clevuelve todos los desperdicios a URENCO, el consorcio alemán-británico-holandés encargado de la construcción de las plantas, e incluso sugirió la intervención cle la Agencia Internacional de Energía Atómica en la materia ${ }^{67}$. El Reino Unido, otro socio de URENCO, seguramente seguirá la posición holandesa. En agosto, los presidentes de Colombia, Costa Rica, Jamaica, Panamá y Venezuela reafirmaron la necesidad que América Latina se mantenga libre de armas atómicas 68 .

Ante estos hechos, con el tiempo Brasil ha debido adoptar una posición más flexible especialmente ahora que requiere con urgencia que Carter permita la licencia de exportación de uranio para operar la planta adquirida a Westinghouse ${ }^{69}$. Además, Brasil ha tenido que buscar apoyo internacional. En esta materia, una de las mayores victorias del Presiclente Geisel ocurrió durante la visita que el Presidente Pérez de Venezuela le hiciera a fines de noviembre. En efecto, ambos mandatarios acordaron criterios comunes respecto al proteccionismo norteamericano y el nuevo orden económico internacional. Para sorpresa de quienes siguen las relaciones entre estos dos estados, Venezuela finalmente aprobó los esfuerzos que hace Brasil por poseer energía nuclear.

Siguiendo las recomendaciones del Informe Linowitz ${ }^{70}$, y con el objeto de realirmar su política en esta materia, Estados Unidos firmó, el 26 de mayo, el Protocolo $\mathrm{X}$ del Tratado de Tlatelolco o Tratado para la Proscripción de las Armas Nucleares en América Latina, el cual requiere que este país remueva sus armas nucleares de Puerto Rico, la zona del Canal de Panamá, las Islas Vírgenes y la

or Los cancilleres de Brasil y Folanda se reunieron en New York en octubre para tratar esta materia. Los ministros acordaron establecer negociaciones para llegar a un acuerdo.

${ }^{a} \mathrm{La}$ reunión de estos presidentes ocurrió entre el 5 y 6 de agosto. En esta ocasión también se discuticron estas materias: el problema del canal de Panamá, el precio mundial del café, la situación de Bélice y el establecimiento de un nuevo orden económico internacional.

on Después de dos años de retraso, se espera que esta planta comience a funcionar a principios de 1978. Al momento de adquirirse csta planta, Brasil firmó un tratado de cooperación nuclear con Estaclos Unidos, a través del cual este pais se comprometió a abastecer a aquél con combustible atómico. La planta comprada a Westinghouse se denomina "Angra I"; las plantas adquiridas a Alemania serán denominadas "Angra II" y "Angra III".

${ }^{70}$ Véace el texto de este tratado en: Vol. 634 Uniled Nations Treaty Series, pp. $281-425$ (1968). Esta convención fue firmada por la mayoría de los estados latinoamericanos el 14 de febrero de $1967 \mathrm{y}$, al mes de mayo de 1977, veintiuno de estos países la habian ratificado (Argentina y Brasil son las grandes excepciones). 
base de Guantánamo. Estados Unidos se encuentran actualmente pre. sionando a Argentina ${ }^{71}$ y Brasil ${ }^{72}$ para que ratifiquen este conve. nio. Desgraciadamente, los esfuerzos norteamericanos podrían traer mayores complicaciones internas en América Latina. En efecto, al poco tiempo de la visita del Canciller Vance a Buenos Aires, ocurrida a fines de noviembre, de la cual se cree que Estados Unidos obtuvo el compromiso de Argentina de ratificar ese tratado, se ha rumoreado y publicado en Charin, un diario con buenos contactos en el gobierno, que ese país desconocería el fallo del arbitraje internacional sobre el Canal del Beagle, emitido en mayo ${ }^{73}$, el cual concedió las islas Nueva, Lennox y Picton a Chile. Muchos observadores piensan que Estados Unidos habría obtenido una cosa a cambio de apoyo en la otra. Ese fallo tiene gran peso jurídico y sólo podría ser impugnado por razones politicas. Naturalmente esta desconcertante actitud de Argentina provocaría graves tensiones con Chile.

Entre los problemas más graves que Carter ha tenido que tratar se encuentra el de los seis a doce millones de inmigrantes ilegales latinoamericanos (especialmente mexicanos) que trabajan en Estados Unidos. Luego de largos estudios y discusiones, el 4 de agosto se fijaron nuevas y más estrictas regulaciones sobre inmigración ${ }^{7 t}$.

\section{VII}

Al momento de ser escrito este artículo (diciembre de 1977) el gobierno de Carter aún no ha cumplido un año y, por ende, es prematuro hacer una evaluación de su política hacia Iberoamérica, al menos que se quiera caer en juicios temerarios.

Los problemas más interesantes han surgido en las áreas de derechos humanos y no proliferación nuclear. El paso más importante está constituido por la firma del nuevo Tratado de Panamá. La materia que pronto comenzará à adquirir más atención es la reanudación de relaciones diplomáticas con Cuba. El punto más criticable es la falta de preocupación por los problemas económicos de América Latina.

La ausencia de una política especial hacia Iberoamérica refleja la idea de Estados Unidos que los problemas económicos de ese conti-

7 Firmó con declaraciones el 27 de septiembre de 1967.

72. Firmó con declaraciones el 9 de mayo de 1967.

73 Este tribunal fue nombrado por la Corona británica $y$ cstuvo compuesto por miembros de la . Corte Internacional de Justicia.

" Los pasos fronterizos serán reforzados y se hace una distinción entre quienes se han encontrado en Estados Unidos antes del 18 de enero de 1970, antes del 18 de enero de 1977 y después del 10 de enero de 1977 . Se da un trato preferencial a los inmigrantes más antiguos. 
nente deben ser tratados en general con los que experimenta el resto del Tercer Mundo. Los países latinoamericanos están de acuerdo con esto, sólo que dan un salto más y reclaman el establecimiento de un nuevo orden económico internacional. A medida que las discusiones sobre este orden avancen, las diferencias entre Estados Unidos e Iberoamérica se ahondarán.

En general, Carter ha tratado de seguir las pautas señaladas en el Informe Linowitz, especialmente respecto a las prioridades que éste fija. En cuanto a las conclusiones del Informe sobre las cuales no se ha hecho mención en el capitulo anterior, es necesario señalar lo siguiente: la ayuda del AID hacia países grandes como Brasil ha disminuido, pero continúa llegando bajo la "Interamerican Foundation", organismo semiautónomo del gobierno norteamericano (véase la recomendación No 14); el Congreso no ha aprobado aún los fondos para la "International Development Association" (véase la recomendación No 15); Carter nombró una persona con el rango de embajador para activar la celebración de la Conferencia de las Naciones Unidas sobre Giencia y Tecnologín (véase la recomendación No 20); Estados Unidos no ha creado nuevas instituciones multinacionales de ciencia y tecnología en América Latina (véase la recomenclación No 2il); y, gracias a la presente ausencia de expropiaciones en Iberoamérica, Garter no se ha visto en la necesidad de redefinir los criterios dados por Nixon sobre aquéllas (véase la recomendación No 22). 